\title{
Compositional effects on PAH and soot formation in counterflow diffusion flames of gasoline surrogate fuels
}

\author{
Sungwoo Park ${ }^{1}$, Yu Wang ${ }^{1,2, *}$, Suk Ho Chung ${ }^{1}$ and S. Mani Sarathy ${ }^{1}$
}

${ }^{1}$ King Abdullah University of Science and Technology (KAUST), Clean Combustion Research Center (CCRC), Thuwal, Saudi Arabia

${ }^{2}$ Wuhan University of Technology, School of Automotive Engineering, Wuhan, P.R. China

*Corresponding author:

Yu Wang

yu.wang@whut.edu.cn

Full length article

Prepared for submission to Combustion and Flame 


\title{
Compositional effects on PAH and soot formation in counterflow diffusion flames of gasoline surrogate fuels
}

\author{
Sungwoo Park ${ }^{1}$, Yu Wang ${ }^{1,2, *}$, Suk Ho Chung ${ }^{1}$ and S. Mani Sarathy ${ }^{1}$ \\ ${ }^{1}$ King Abdullah University of Science and Technology (KAUST), Clean Combustion Research Center \\ (CCRC), Thuwal, Saudi Arabia \\ ${ }^{2}$ Wuhan University of Technology, School of Automotive Engineering, Wuhan, P.R. China
}

\begin{abstract}
Gasoline surrogate fuels are widely used to understand the fundamental combustion properties of complex refinery gasoline fuels. The compositional effects on polycyclic aromatic hydrocarbons (PAHs) and soot formation were investigated experimentally for gasoline surrogate mixtures comprising n-heptane, iso-octane, and toluene in counterflow diffusion flames. A comprehensive kinetic model for the gasoline surrogate mixtures was developed to accurately predict the fuel oxidation along with the formation of PAHs and soot in flames. This combined model was first tested against ignition delay times and laminar flame speeds data. The proposed model for the formation and growth of PAHs up to coronene $\left(\mathrm{C}_{24} \mathrm{H}_{12}\right)$ was based on previous studies and was tested against existing and present new experimental data. Additionally, in the accompanied soot model, PAHs with sizes larger than (including) pyrene were used for the inception of soot particles, followed by particle coagulations and PAH condensation/chemical reactions on soot surfaces. The major pathways for the formation of PAHs were also identified for the surrogate mixtures. The model accurately captures the synergistic PAH formation characteristics observed experimentally for n-heptane/toluene and isooctane/toluene binary mixtures. Furthermore, the present experimental and modeling results also elucidated different trends in the formation of larger PAHs and soot between binary n-heptane/iso-octane and ternary nheptane/iso-octane/toluene mixtures. Propargyl radicals $\left(\mathrm{C}_{3} \mathrm{H}_{3}\right)$ were shown to be important in the formation and growth of PAHs for n-heptane/iso-octane mixtures when the iso-octane concentration increased; however, reactions involving benzyl radicals $\left(\mathrm{C}_{6} \mathrm{H}_{5} \mathrm{CH}_{2}\right)$ played a significant role in the formation of PAHs for $\mathrm{n}$ heptane/iso-octane/toluene mixtures. These results indicated that the formation of PAHs and subsequently soot was strongly affected by the composition of gasoline surrogate mixtures.
\end{abstract}

Keywords: PAHs; Soot; Gasoline surrogate fuel; Chemical kinetic model; Counterflow diffusion flame 


\section{Introduction}

Particulate matter emissions are presently a concern in gasoline fueled direct-injection spark-ignition (DISI) engines. To better understand the combustion behavior of refinery gasoline fuels [1-7] and their emission characteristics, surrogate fuels are typically adopted for the development of predictive tools. Gasoline contains straight and branched-chain aliphatics, aromatics, alkenes, and cycloalkanes [1]. It has been shown that toluene primary reference fuels (TPRFs), the ternary mixtures of n-heptane, iso-octane, and toluene can match the ignition quality of gasoline fuels [8,9]. The presence of aromatics in gasoline fuels and their surrogates enhances the formation of polycyclic aromatic hydrocarbons (PAHs) and soot, which may cause adverse health and environmental problems [10]; however, fundamental studies on the formation of PAHs and soot from real fuel combustion are rather limited [1,11-19]. In particular, direct fuel injection strategies aimed at enhancing fuel efficiency in gasoline engines often result in increased emission of smaller sized particulate matters, which are being regulated under new stringent emission laws. An accurate prediction of PAH concentrations, which are molecular precursors for soot formation and growth, is required to understand the effects of gasoline fuel composition on sooting characteristics, such as soot volume fraction, number density, and particle size distribution.

Several studies have been performed on the formation and growth of PAHs during the combustion of gasoline relevant fuels. Inal and Senkan [11] quantified the concentration profiles of PAH species in several fuel-rich laminar premixed flames of n-heptane at atmospheric pressure using a gas chromatography/mass spectrometry technique. Choi et al. [12] investigated PAH and soot formation characteristics for gasoline surrogate fuels in counterflow diffusion flames using laser-induced fluorescence (LIF) and laser-induced incandescence (LII) techniques. Detailed analysis of their experimental results indicated an interesting synergistic effect on PAHs in the n-heptane/toluene and iso-octane/toluene mixture flames, meaning the enhanced PAH formation for certain fuel mixtures as compared to corresponding single fuel components, similar to the synergistic effects observed for gaseous fuel mixtures [13-15]. The experimental [16,17] and numerical [18] studies of the effects of fuel composition on soot formation of binary PRF/TRF fuels in coflow diffusion flames have been conducted using methane flames doped with different blends of gasoline surrogate components. Li et al. [19] studied toluene decomposition and PAH formation in premixed flames at low pressure using synchrotron-based vacuum ultraviolet photoionization mass spectrometry. D'Anna et al. [20] investigated the process of soot growth in an 
$\mathrm{n}$-heptane premixed flame and found that the formation of larger particles in the aromatic-doped n-heptane flame. Mosbach et al. [21] presented a detailed model for soot formation in internal combustion engines coupling a gas-phase kinetic mechanism for primary reference fuel (PRF, mixtures of n-heptane and iso-octane). Blanquart et al. [1] and Marchal et al. [22] investigated PAH growth processes and proposed kinetic models for the formation of soot precursors in the combustion of engine relevant fuels. Wang and co-workers proposed reduced mechanisms for TPRF mixtures [23] and n-heptane/n-butanol mixtures [24], and tested their applications in engine simulations. Based on previous skeletal models [22], Raj et al. [25] presented a mechanism for gasoline surrogate fuels (KAUST PAH Mech 1; KM1) by adding relevant reactions using the density functional theory and transition state theory to account for the growth of PAHs up to coronene (A7, $\mathrm{C}_{24} \mathrm{H}_{12}$ ); these updates offered improvements in predicting PAH concentrations for $n$-heptane premixed flames [11] and diffusion flames of binary mixtures of toluene/n-heptane and toluene/iso-octane.

A closer look at existing literature reveals that among the previous studies for gasoline surrogate fuels, systematic investigations on the effects of fuel compositions on $\mathrm{PAH} /$ soot formation are rather limited, especially for ternary TPRF mixtures in nonpremixed systems. Considering that TPRF mixtures were shown to better represent fundamental combustion properties of real gasoline fuels [26], and that a major contribution of soot emission in direct-injection gasoline engines is from inhomogeneous combustion by fuel stratification, detailed investigation of sooting characteristics of TPRF in diffusion flames are of great interests. As such, the purpose of the present study is set to expand the experimental data available for gasoline surrogate fuels in diffusion flames to better understand the effects of fuel blending on PAH formation, with a special focus on TPRF mixtures. Furthermore, an updated detailed chemical kinetic model for TPRF gasoline surrogate mixtures was also developed, with an emphasis on the formation of PAHs, to simulate and elucidate the experimental observations.

\section{Experiment}

In order to obtain a systematic understanding of the chemical cross-linking effects among TPRF mixture components in nonpremixed flames, a new set of experiments were conducted using a counterflow diffusion flame configuration. A schematic including a counterflow burner and laser diagnostic systems (LII) is shown in Fig.1. 
Details of the counterflow burner system have been reported previously [12]. Briefly, the burner consists of two opposing nozzles with an inner diameter of $10 \mathrm{~mm}$ and a separation distance of $8 \mathrm{~mm}$. Concentric slits (2 $\mathrm{mm}$ wide) surrounding the nozzles provide shield nitrogen to prevent the flames from being affected by ambient air and to avoid the formation of secondary diffusion flames in globally fuel-rich conditions. The average flow velocities at the nozzle exits for both the fuel and oxidizer streams were kept at $20 \mathrm{~cm} / \mathrm{s}$ for all experiments. Gas and liquid flow rates were controlled by thermally-based mass flow controllers and precision syringe pumps, respectively. The oxidizer stream was composed of $\mathrm{O}_{2}$ and $\mathrm{N}_{2}$ with various $\mathrm{O}_{2}$ mole fractions and the fuel stream was $65 \% \mathrm{~N}_{2}$ diluted on a molar basis. To vaporize the liquid fuels, a commercially-available evaporation system was used with $\mathrm{N}_{2}$ as the carrier gas. The fuel supply line and the fuel nozzle were both electrically heated to temperatures of 180 and $150^{\circ} \mathrm{C}$, respectively, to prevent re-condensation of the vaporized fuels. The oxidizer nozzle was maintained at room temperature using a water-cooled system.

Laser-induced fluorescence (LIF) and laser-induced incandescence (LII) techniques were used to measure the relative PAH concentrations and soot volume fractions, respectively. For the LIF experiment, the fourth harmonic of a pulsed Nd-YAG laser $(266 \mathrm{~nm})$ was used as the excitation beam. The energy of the laser beam was continuously monitored by an energy meter, and was reduced through several 30/70 UV beam-splitters to about $1 \mathrm{~mJ} /$ pulse. It has been tested that at such a low energy level, the laser beam did not induce detectable LII signals, such that interference in the LIF signals by soot incandescence could be minimal. The incident beam was manipulated by a combination of cylindrical and spherical lenses to form a vertical laser sheet with a height of $8 \mathrm{~mm}$, whose spatial energy distribution was tested using a knife-edge technique. The broadband LIF signals from PAH molecules were then detected using an ICCD camera with various filters (330, 400, 450 and 500 nm). The filter bandwidths were $10 \mathrm{~nm}$ (FWHM) for the $330 \mathrm{~nm}$ filter and $40 \mathrm{~nm}$ (FHWM) for the 400, 450 and $500 \mathrm{~nm}$ filters. The synchronization between the gate time of the ICCD camera and the arrival of the laser pulse was obtained by performing elastic scattering experiments before the actual measurement, in which the gate width and gate delay were set at $50 \mathrm{~ns}$ and 0 , respectively, to capture the fluorescence signal as soon as the laser arrives at the flame. To increase the signal to noise ratio, the measured LIF signals were averaged over 600 laser shots after subtracting the background signals. The uncertainties of the LIF signal intensities (estimated from standard deviation) was around $4.5 \%$.

The LII experiment employs a similar optical arrangement as the LIF setup, with the primary difference being the wavelength and energy of the laser beam. Unlike the LIF setup in which a UV beam was used, the 
fundamental near-infrared emission of the Nd-YAG laser at $1064 \mathrm{~nm}$ was used as the excitation beam. The energy of the beam could be continuously tuned by using a combination of a zeroth-order half-wave plate and a polarizing beam splitter and it was slightly above the saturation threshold to be within the plateau regime such that the LII intensity will not depend on laser energy. The LII signal from the laser-heated soot particles were then detected at $400 \mathrm{~nm}$ using an ICCD camera with a gate width of $80 \mathrm{~ns}$ and no gate delay. Due to the short gate width $(80 \mathrm{~ns})$, the contribution of soot radiation at flame temperature (i.e., flame emission) to the

LII signal is negligible. This fact has been confirmed by recording flame emission background image without the laser. Despite this, we still subtract the background signal from the LII data. Therefore, the effects of flame emission are minimized.

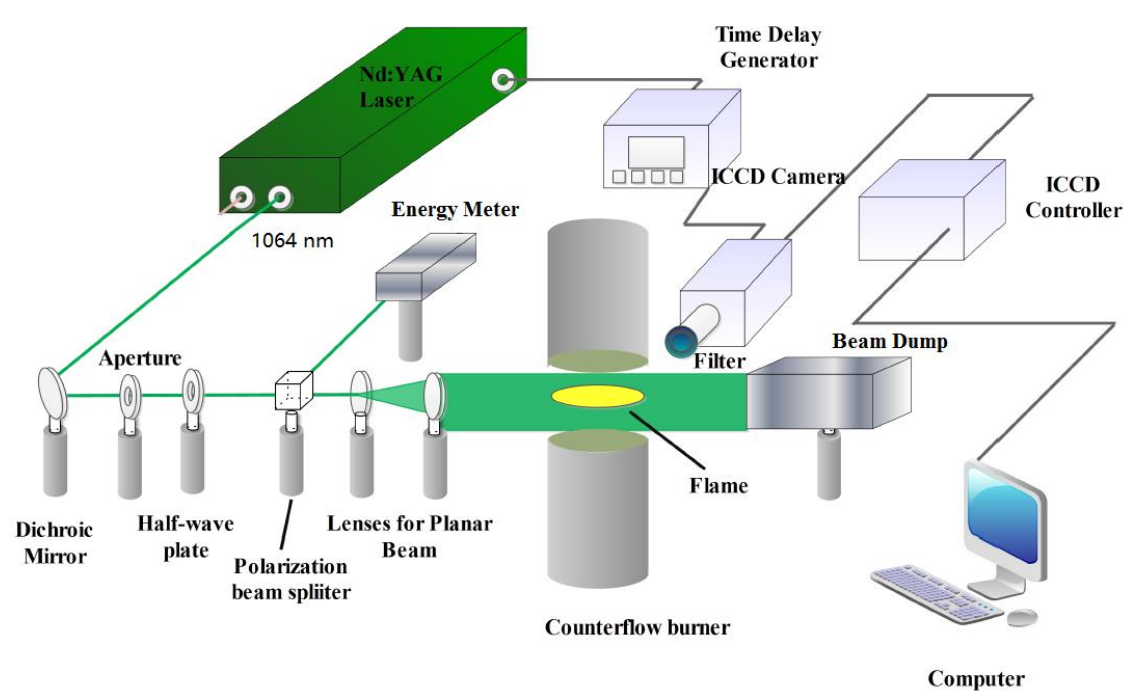

Fig. 1. Schematic of the experimental setup including the burner and the laser diagnostic (LII) system.

\section{Kinetic Model Development}

The chemical kinetic model (KAUST-Aramco PAH Mech 1-GS) presented here is developed using a hierarchical approach [27]. The detailed model includes both low- and high-temperature chemistry. The AramcoMech 1.3 [28] for the oxidation of small hydrocarbons, including updated propene sub-chemistry [29], was used as the base mechanism with additional reactions for hydrocarbon oxidation up to benzene [30]. PAH formation and growth reaction pathways from the KAUST PAH mechanisms (KM1, KM2) [25, 31] were then added. In a previous study [25], the density functional theory (DFT) and the transition state theory (TST) were used to evaluate the rate constants for several PAH reactions, and new pathways for the growth of PAHs up to coronene $\left(\mathrm{C}_{24} \mathrm{H}_{12}\right)$ were also explored to improve the model prediction of PAH concentrations in various flame configurations. The comprehensive detailed LLNL gasoline surrogate sub-mechanism [32] was added to 
represent the oxidation of $\mathrm{n}$-heptane, iso-octane, and toluene across a range of engine-relevant temperatures and pressures. Additionally, PAH growth reactions initiated by propargyl $\left(\mathrm{C}_{3} \mathrm{H}_{3}\right)$ radical addition to naphthalene (A2) leading to the formation of pyrene (A4) were added [33].

The present study follows the same notation for aromatic species with 1-7 rings (A1-A7) as described in Ref. [25]. (The list of major species discussed in the present work is given in the Supplementary Material 1). Only a brief description is presented herein; readers are referred to [25] for a more detailed description of PAH growth pathways. The reactions involving odd-carbon number species such as propargyl, cyclopentadienyl $\left(\mathrm{C}_{5} \mathrm{H}_{5}\right)$, benzyl $\left(\mathrm{C}_{6} \mathrm{H}_{5} \mathrm{CH}_{2}\right)$, and indenyl $\left(\mathrm{C}_{9} \mathrm{H}_{7}\right)$ radicals on the formation of PAHs are included for PAH growth pathways [25] along with the hydrogen-abstraction- $\mathrm{C}_{2} \mathrm{H}_{2}$-addition (HACA) mechanism [19]. Most reactions for PAH growth beyond A4 are based on the addition of acetylene $\left(\mathrm{C}_{2} \mathrm{H}_{2}\right)$ to PAH radicals. The pressure-dependent rate constants suggested by Kern et al. [34] are used for the decomposition of cyclopentadienyl radical to acetylene and propargyl radical. This study employs the rate constants of Zhang et al. [35] for unimolecular decomposition of toluene, and the reaction rates of Marchal et al. [22] is adopted for the reaction between toluene and $\mathrm{H}$ radical to produce benzene and methyl radical.

All the simulations were conducted in CHEMKIN PRO [36] using appropriate reactor modules. Simulations of ignition delay times were conducted with both the high- and low temperature reactions. While simulations for premixed and nonpremixed flames adopted only the high-temperature mechanism to reduce computation times, wherein the difference by including the low-temperature reactions were minimal. The proposed comprehensive model includes 2021 species and 8688 reactions, and the CHEMKIN input files are provided in Supplementary Material 2. A smaller kinetic model (574 species and 3379 reactions) comprising only hightemperature reactions is also provided in Supplementary Material 3 to facilitate flame simulations. Previous work has shown that high-temperature sub-mechanisms derived from comprehensive detailed mechanisms are suitable for simulating premixed and diffusion flame structure [37-40].

\section{Results and Discussion}

Before detailed presentation discussion of the research results, it is worthwhile to point out that throughout this study, we have used the results of many previous experimental investigations in addition to new flame experiments we conducted here. For ease of reference, we summarized in Table. S1 of the supplementary material the conditions of all experiments that are used in the current study. 


\subsection{Baseline experimental results}

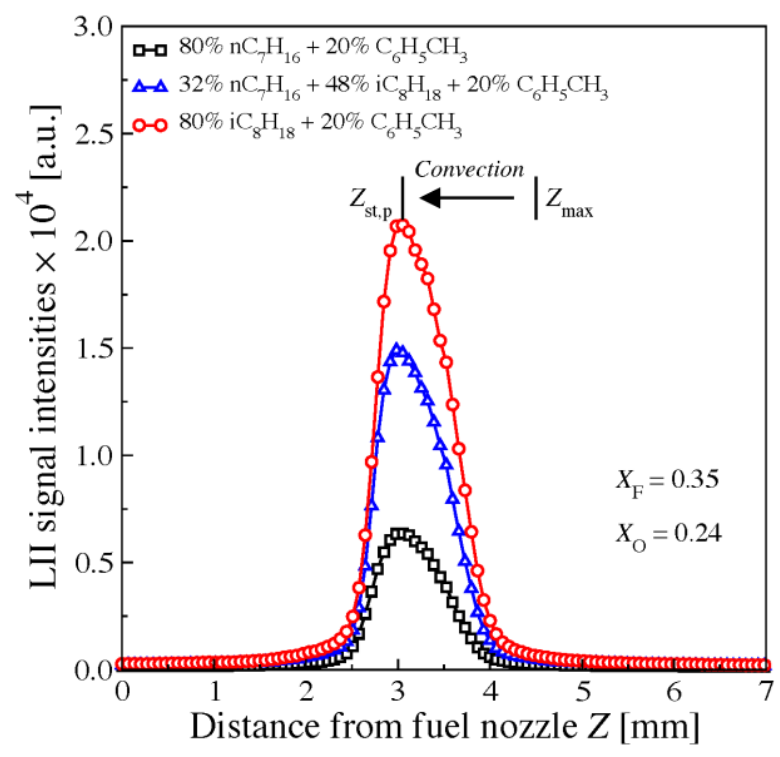

Fig. 2 Typical relative soot loading profiles measured by the LII technique in several TPRF counterflow diffusion flames.

Figure 2 shows typical soot volume fraction (SVF) profiles, as represented by the LII signal intensities as a function of distance from the fuel nozzle $(Z)$ for the tested TPRF flames with various fuel mixture compositions. Here, $X_{\mathrm{F}}$ and $X_{\mathrm{O}}$ are the mole fractions of fuel and oxygen in the fuel and oxidizer streams at the respective nozzle exits. $Z_{\max }$ and $Z_{\mathrm{st}, \mathrm{p}}$ indicate the locations of maximum temperature and particle stagnation plane, respectively. The data for three sets of experiments are provided at a fixed toluene percentage (20\% vol) in the fuel balanced with n-heptane, iso-octane and their mixture.

Several interesting features can be noticed. Firstly, the profiles are skewed appreciably toward the fuel side, a fact that has been observed previously and indicates that these counterflow flames are of the soot formation (SF) type [41], corresponding to the case when the flame is located on the oxidizer side from the stagnation plane. Soot particles start to form close to the fuel side of the flame (located at $Z_{\max }$ ) and then continue to grow along the direction of bulk convective flow toward the particle stagnation plane, $Z_{\mathrm{st}, \mathrm{p}}$. Near $Z_{\mathrm{st}, \mathrm{p}}$, the soot volume fractions decrease rapidly since soot particles, with very low mass diffusivity, are not likely to penetrate and will thus be leaked through the stagnation plane. Secondly, the replacing n-heptane in the fuel with iso-octane, while keeping the toluene ratio constant, has an appreciable effect in increasing soot loading. In fact, this compositional effect is one of the foci of this study and will be elaborated in detail later.

Although soot loadings are represented by LII signal intensities in arbitrary units in Fig. 2, one can convert them to absolute soot volume fractions, provided that additional experiments such as light extinction/scattering (LES) techniques are performed to calibrate the LII data. We performed such calibration (refer to our previous 
papers for details about the LES techniques $[42,43]$ ) at one flame condition (iso-octane fuel, $X_{\mathrm{F}}=0.35, X_{\mathrm{O}}=$ 0.33 ) and the result shows that the scaling factor between LII data and soot volume fraction is 10000 LII signal counts to $0.446 \mathrm{ppm}$. Additional LES experiments were conducted at other flame conditions (varying fuel components and varying oxygen mole fractions) to check quantitatively the linear relationship between LII signals and SVF and the results are presented in Fig. 3. Primary reference fuels (PRFs, binary mixtures of nheptane and iso-octane) were used by varying iso-octane ratio $\left(R_{\mathrm{i}}\right)(\mathrm{a})$ and varying oxygen mole fraction (b).
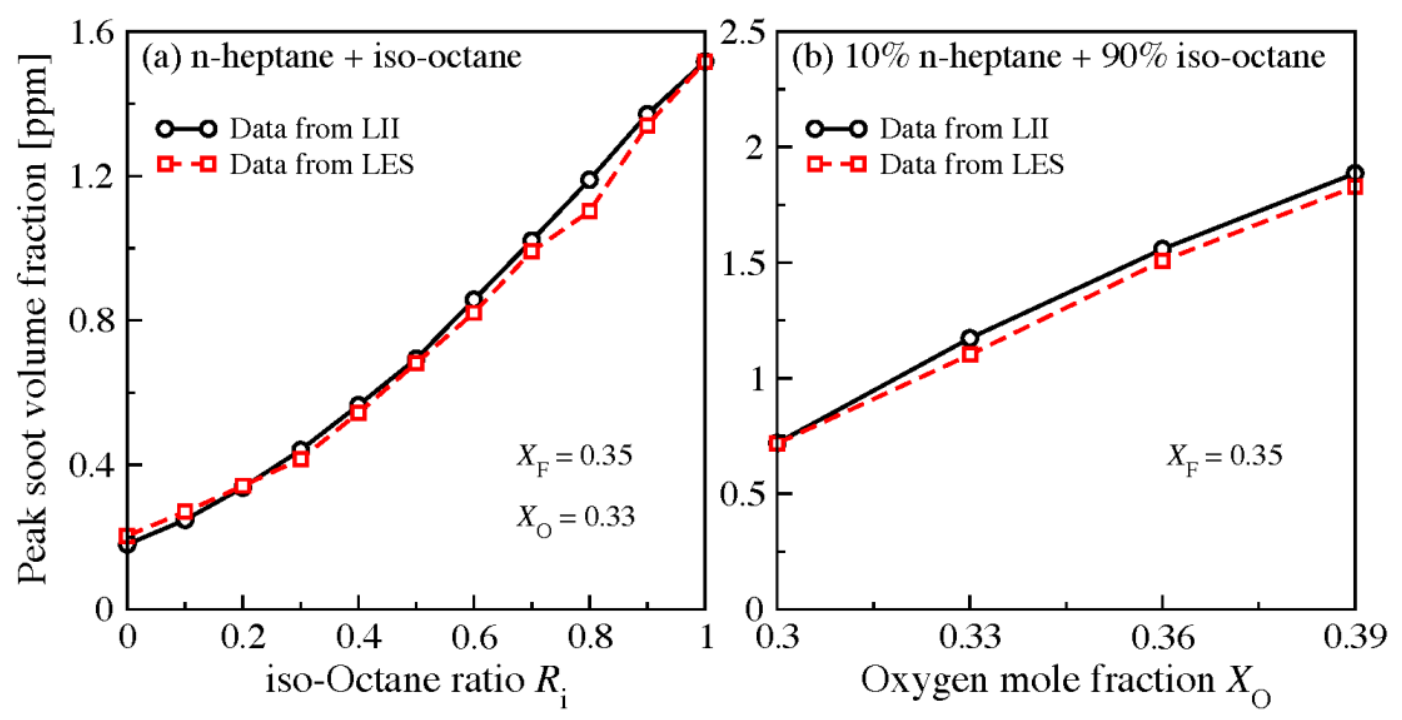

Fig. 3 Calibration and cross-validation of LII-measured peak soot volume fraction in various flames by those obtained by the light extinction/scattering (LES) method: peak soot volume fractions in PRF flames with (a) varying iso-octane ratio and (b) varying oxygen mole fractions.

The results show that both experimental techniques satisfactorily agree with each other. This demonstrates the validity of using LII signal intensity to represent soot volume fraction, and also helps to cross-validate both experimental setups used in this study. However, it is worthwhile to point out that the LES measurement, which is a line-of-sight technique, typically takes much longer time as compared to LII measurement due to the need to scan, point by point, the whole domain of interests before field reconstruction using the Abel inversion. The soot measurements presented in later sections are all performed using the LII technique. 


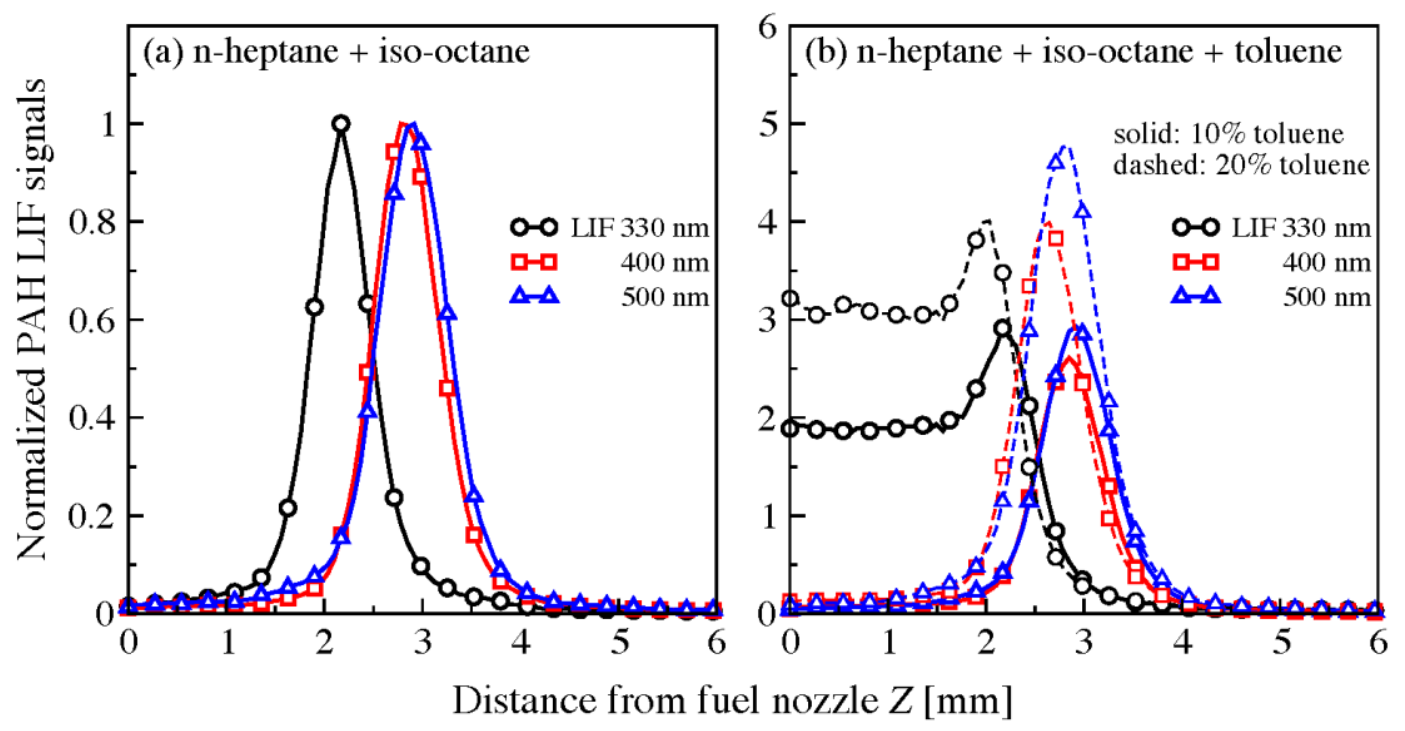

Fig. 4 Normalized profiles of LIF signals for (a) n-heptane/iso-octane (40/60\%) and (b) n-heptane/iso-octane/toluene (solid: 36/54/10\%, dashed: 32/48/20\%) mixture flame.

Figure 4 shows typical centerline profiles of the LIF signals (detection at 330, 400 and $500 \mathrm{~nm}$ ) for (a) nheptane/iso-octane and (b) n-heptane/iso-octane/toluene mixtures. The data are normalized with the maximum intensities of n-heptane/iso-octane mixtures at each detection wavelength. Note that the LIF intensities have not been corrected for the camera quantum efficiency and filter transparency differences at the detected wavelengths and therefore, only qualitative comparisons across different detection wavelengths for a specific flame are expected. Thus, the following normalized data are used to represent relative PAH concentrations among flames with different fuel compositions. Detailed PAH and soot comparisons for PRF/TPRF mixtures are discussed in later sections. The maximum PAH LIF locations are closer to the fuel nozzle when compared to the maximum soot LII signals (near $Z=3 \mathrm{~mm}$ for $40 / 60 \%$ mixture) in Fig. 2, indicating that PAHs are precursors to soot. LIF signals at higher detection wavelengths are believed to represent larger PAH molecules [44-46], although pinpointing a specific PAH molecule is not yet possible due to the complex broadband absorption/emission spectra for PAH species. The result in Fig. 4 is in agreement with this trend. The LIF signals of TPRF mixtures detected at $330 \mathrm{~nm}$ in Fig. 4b show LIF signal between the fuel nozzle and flame zone, which can be attributed to the fluorescence emissions of toluene [47].

\subsection{Mechanism validation}

Before discussing the formation of PAHs and soot, the present mechanism was validated against a wide range of experimental data including shock tube ignition delay times, laminar burning velocities, species 
concentration profiles in premixed and partially premixed flames. The purpose here is to test the mechanism's capability to predict fundamental combustion properties, and thus its potential application in simulating real combustion devices such as internal combustion engines.

Figure 5 shows the experimental and computed ignition delay times for PRF, toluene/n-heptane, and TPRF mixtures at various pressures $P_{0}$ and equivalence ratios $\phi$. Numerically, the ignition delay times were calculated by running homogeneous constant volume simulations with the adiabatic homogenous reactor model in CHEMKIN PRO [36]. The comprehensive detailed kinetic mechanism including high- and low-temperature chemistry was used. In the simulations, the ignition delay time corresponds to the point of maximum temperature $(T)$ rise rate with time $(t)$ of $\mathrm{d} T /\left.\mathrm{d} t\right|_{\max }$.

Figure 5a compares the experimental ignition delay times of various PRF fuels [48] against initial temperature $\left(T_{0}\right)$ with present model predictions, which generally capture the negative temperature coefficient (NTC) behavior and the differences between the PRF fuels. Figure 5 also shows the comparison of ignition delay times for n-heptane/toluene mixture (65\% toluene and 35\% n-heptane in liquid volume) [49] and threecomponent (surrogate B [50]: 69\% iso-octane, 17\% n-heptane and 14\% toluene in liquid volume) mixture. As can be seen, the simulated results using the present mechanism agrees with the experimental ignition data, although the model slightly over-estimates ignition delay times with a maximum difference of about a factor of two. Overall, the present model captures the ignition delay times for various pressures, temperatures, and fuel compositions.
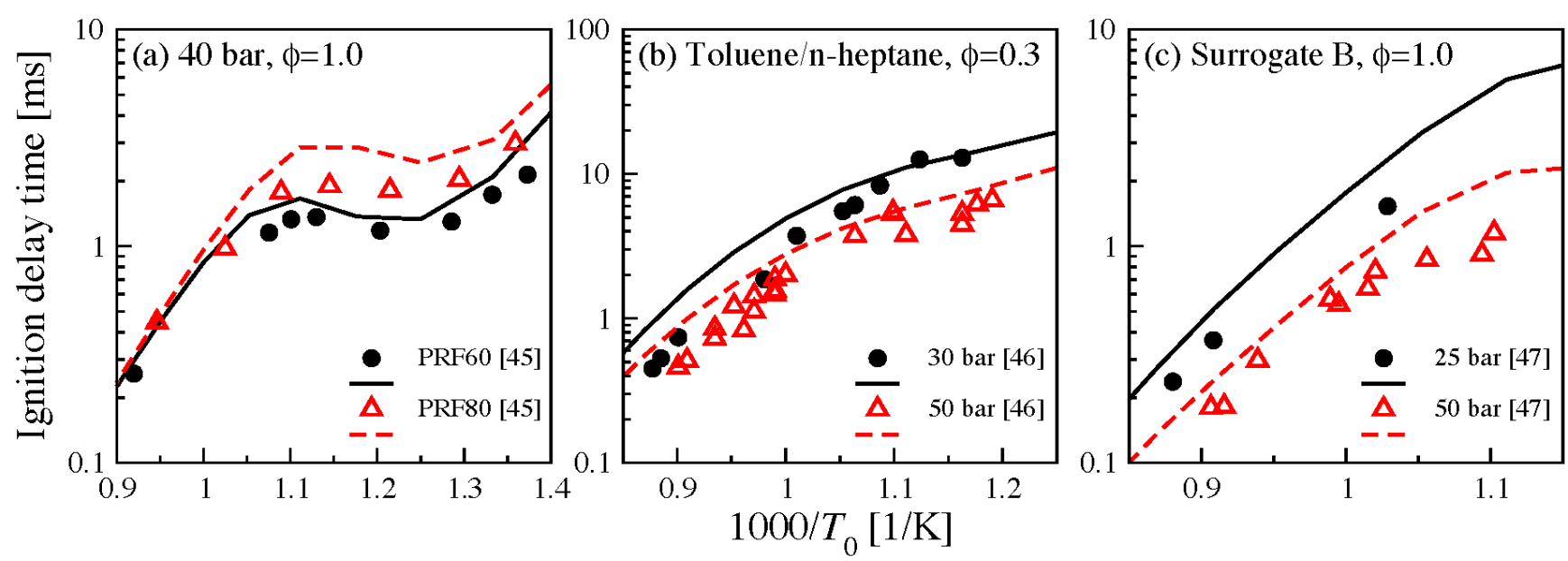

Fig. 5. Ignition delay times for the validation of present mechanism for PRF, toluene/n-heptane, and TPRF mixtures. Experimental data from [45-47] (symbols) are compared to calculations (lines). 
Figure 6 shows the comparisons between the computed laminar burning velocities of n-heptane, iso-octane, and toluene using the proposed mechanism and those obtained from experimental data [51-55]. Simulations of laminar burning velocity were conducted with the PREMIX flame code in CHEMKIN PRO [36], using the detailed high-temperature mechanism. The simulations accounted for thermal diffusion (i.e., Soret effect), assumed mixture averaged transport properties, and were converged with approximately 200 grid points for most cases (GRAD 0.1, CURV 0.1). The model well captures the stoichiometric laminar burning velocities of n-heptane, iso-octane, and toluene at atmospheric pressure, while somewhat under-estimating them in the fuelrich region. The model also well reproduces the maximum burning velocities observed at the equivalence ratio of 1.1, while slightly over-estimates the laminar burning velocities of toluene at 3 bar and equivalence ratios between 0.9 and 1.2. The laminar burning velocities of three-component (77.4\% iso-octane, 17.6\% n-heptane and 5\% toluene in liquid volume) [26] gasoline surrogate mixtures were also tested, as shown in Fig. 6c. The model slightly over-estimates laminar burning velocity data below the equivalence ratio of 1.2 at the atmospheric pressure. While high-pressure experimental data are well captured by the model except for the fuel-richest condition. The results also show that the model well reproduces the experimentally observed trend that laminar burning velocities decrease with increasing pressure.
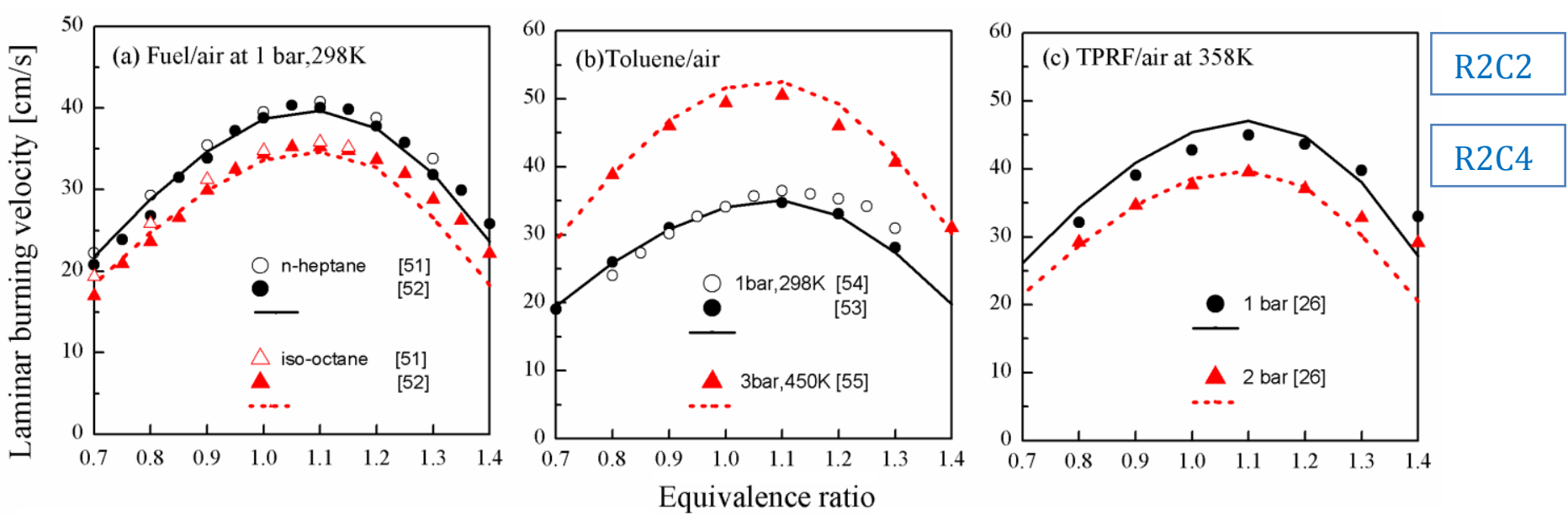

Fig. 6. Laminar burning velocities for the validation of present mechanism. Experimental data from [51-55] and [26] (symbols) are compared to calculations (lines).

It is worthwhile to mention here that the PAH sub-mechanism included in the present mechanism is not important in predicting the ignition time and burning velocities. There is practically no difference for ignition delay times for fuel-rich $(\phi=2)$ TPRF (Surrogate B) mixtures without the PAH sub-mechanism. In case of 
laminar burning velocity, the maximum difference is less than $0.7 \mathrm{~cm} / \mathrm{s}$ (within experimental error) for fuel-rich

\section{$(1.1<\phi<1.4)$ TPRF mixtures at $358 \mathrm{~K}$.}

Apart from the above mentioned global combustion properties of ignition delay time and laminar burning velocity, the present mechanism is in addition tested against fuel-rich premixed flames of n-heptane and isooctane $[11,56]$, as well as partially premixed counterflow flames in Ref. [57] for detailed profiles of species mole fractions. Premixed fuel-rich n-heptane and iso-octane flames $(\phi=1.9)$ at atmospheric pressure [56] were simulated with the burner-stabilized premixed flame module in CHEMKIN PRO [36] and the results are shown in Fig. 7, along with experimental data for concentration profiles of reactant fuel, major products $\left(\mathrm{CO}, \mathrm{CO}_{2}, \mathrm{H}_{2}\right.$ and $\left.\mathrm{H}_{2} \mathrm{O}\right), \mathrm{C}_{2}-\mathrm{C}_{3}$ intermediate species, and benzene $\left(\mathrm{C}_{6} \mathrm{H}_{6}\right.$ or A1) against the height above burner (HAB). Note that the measured temperature profiles were used as inputs for the simulation (i.e., the gas energy equation was not solved) and both KM1 [25] and the present model were used for comparison purposes. As can be seen, both KM1 and the present model show good agreement with experimental data, but the maximum mole fraction of benzene and its location are better predicted by the present model.
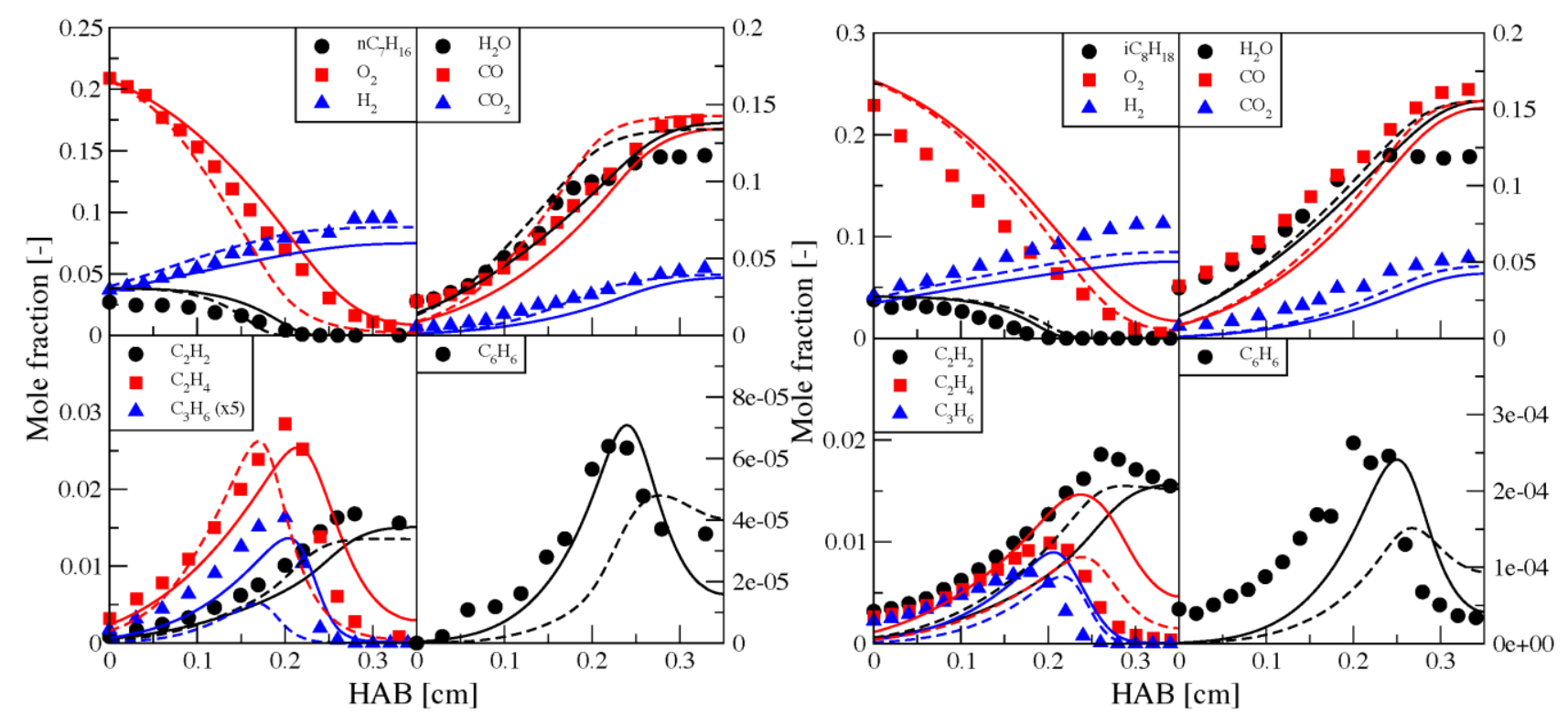

Fig. 7. Comparison between experimental [53] and calculated (dashed: KM1[22], solid: present mechanism) mole fractions of reactants, intermediate species, major products, and benzene in $\mathrm{n}$-heptane (left) and iso-octane (right) premixed flames (1atm, $\phi=1.9$, fuel $/ \mathrm{O}_{2} / \mathrm{N}_{2}$ flames)

To confirm the present model's capability in predicting PAH species, which are important soot precursors a fuel-rich n-heptane/oxygen/argon premixed flame was also modelled, for which experimental mole fraction profiles of benzene (A1), naphthalene (A2), phenanthrene (A3) and pyrene (A4) were measured by Inal and Senkan [11]. Comparisons between the experimental and kinetic modeling simulations are shown in Fig. 8. The 
simulation results using previously published PAH mechanisms (Mech I from Marchal et al. [22] and Mech II from Blanquart et al. [1]) are also included. The present model predicts reasonably well the measured concentrations of larger PAH (A3 and A4) molecules and the results are similar to those of KM1. Note that the previously reported mechanisms (Mech I and Mech II) reasonably capture the concentrations of $\mathrm{C}_{6} \mathrm{H}_{6}$ and A2, but they significantly under-estimate the concentrations of A3 and A4. Note for very small HAB, as Inal et al. have mentioned in Ref [11], the measurements could be influenced by interactions between the sampling probe and the burner surfaces. As a result, meaningful comparisons between modelled and experimental data are only expected at large HABs. The simulated results for benzene and A2 using the present mechanism and KM1 at the large HABs are both reasonably matched with the experimental data within the experimental uncertainties. On the other hand, the differences in the numerical predictions for A3 and A4 between the present mechanism and earlier model indicate that additional PAH reactions, especially those involving oddcarbon number species such as propargyl, cyclopentadienyl, benzyl and indenyl radicals, are required besides the conventional HACA pathways to account for the formation and growth of large PAHs (these additional reactions are listed and discussed in a previous study and are also included in the mechanism file available as supplementary material). Therefore, the present model's ability to capture larger PAHs is of great importance to the present work since larger aromatics lead to soot inception [58].

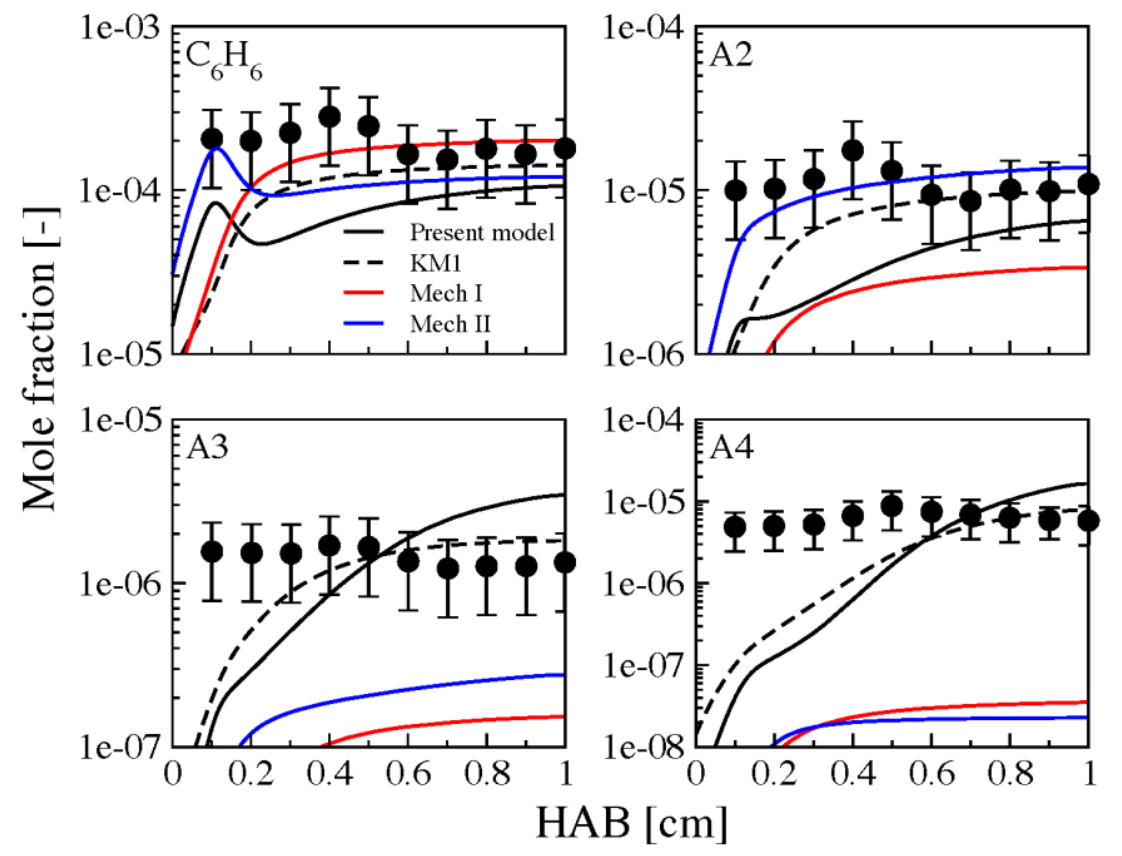

Fig. 8. Comparison between experimental [11] and calculated mole fractions of benzene and various PAHs in an nheptane premixed flame (1atm, $\left.\mathrm{nC}_{7} \mathrm{H}_{16} / \mathrm{O}_{2} / \mathrm{Ar}=5.33 / 29.7 / 64.97\right)$ 
Berta et al. [57] investigated the detailed chemical structure of counterflow partially premixed n-heptane flames, in which the fuel stream was pre-vaporized n-heptane/air mixture $(\phi=10)$ and the oxidizer was air at room temperature. The separation distance between the nozzles of the counterflow burner was $15 \mathrm{~mm}$ and the fuel nozzle was heated to maintain the fuel/air stream at a temperature of $400 \mathrm{~K}$ at the burner exit. The experimental results showed a double flame structure that is characterized by separate premixed and nonpremixed reaction zones. The present kinetic model was used to simulate this flame and the comparisons between experimental and computed concentrations of reactants, major products $\left(\mathrm{CO}, \mathrm{CO}_{2}, \mathrm{H}_{2}\right.$ and $\left.\mathrm{H}_{2} \mathrm{O}\right), \mathrm{C}_{2}$ intermediate species, and benzene $\left(\mathrm{C}_{6} \mathrm{H}_{6}\right)$ are shown in Fig. 9. The present model shows a reasonable agreement with experimental data at premixed and diffusion flame zones.
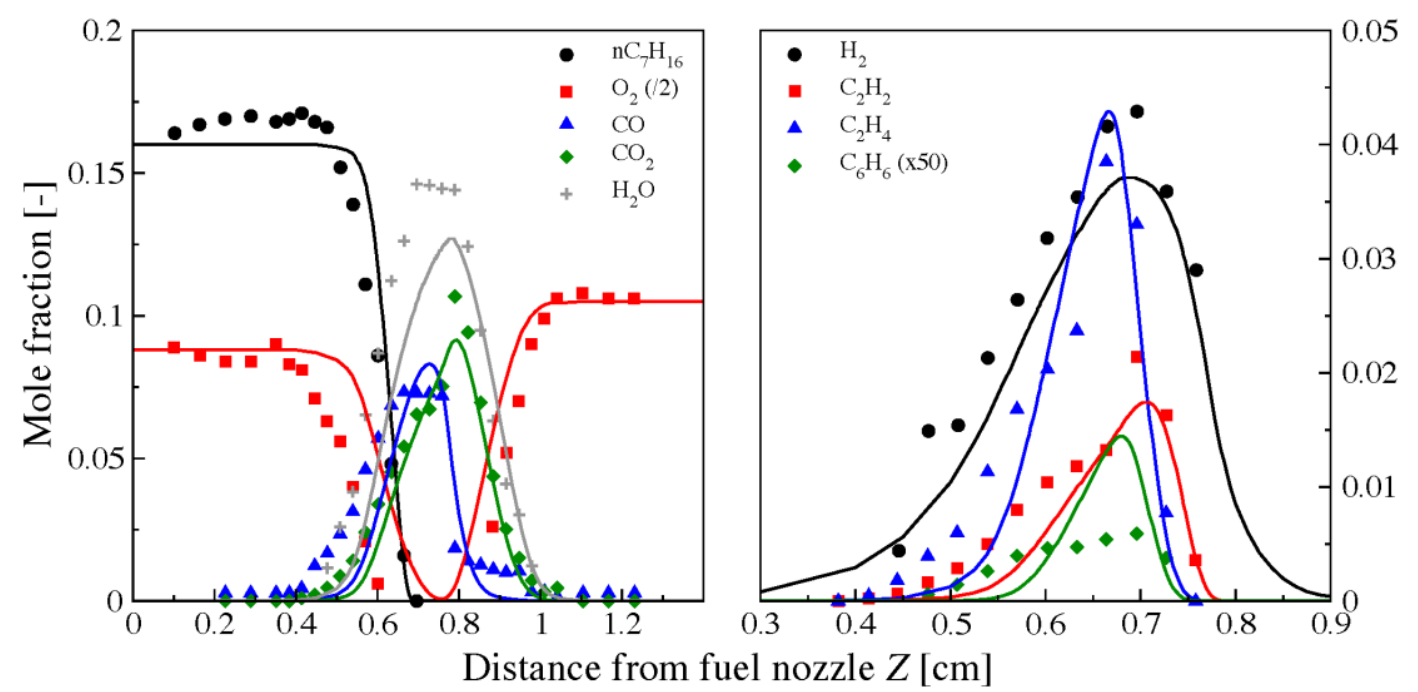

Fig. 9. Comparison between experimental [57] and calculated mole fractions of reactants, intermediate species, major products, and benzene in $\mathrm{n}$-heptane partially-premixed flames (1atm, $\phi=10$ in fuel nozzle)

\section{3 n-Heptane/iso-octane flames}

Following the aforementioned mechanism validation studies, we shift focus to the effect of fuel composition on PAH and soot formation in counterflow diffusion flames (CDF) of PRF mixtures. PAH LIF signals were measured at different wavelengths for $\mathrm{n}$-heptane/iso-octane mixtures by varying the iso-octane ratio $\left(R_{\mathrm{i}}\right)$, defined as the molar ratio of iso-octane, to provide better understanding of the formation of PAHs in PRF mixtures. The oxidizer stream was composed of $24 \% \mathrm{O}_{2}$ and $76 \% \mathrm{~N}_{2}$ and the fuel stream was $65 \% \mathrm{~N}_{2}$ diluted on molar basis for PAH LIF experiment. 


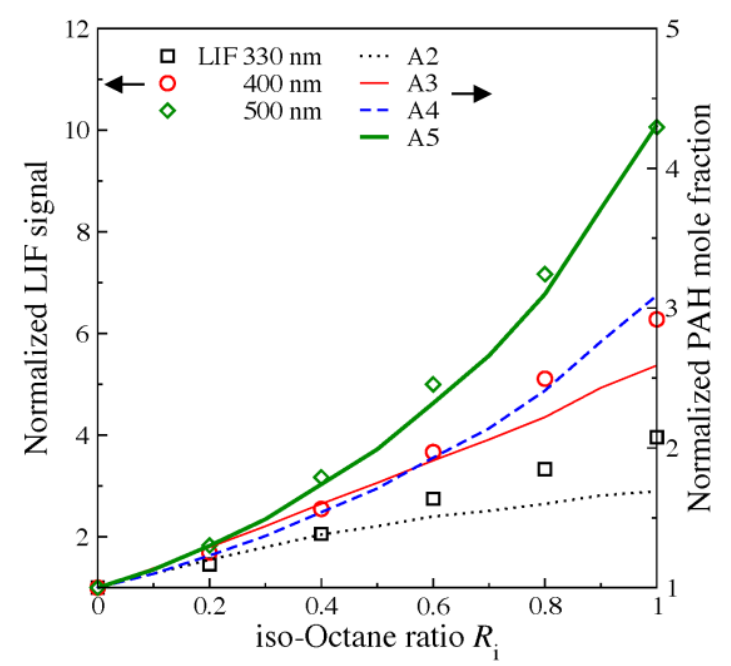

Fig. 10. Normalized maximum LIF signals and computed PAHs for n-heptane/iso-octane mixtures in SF conditions with fuel diluted with $65 \% \mathrm{~N}_{2}$.

Figure 10 shows the normalized (at iso-octane ratio $R_{\mathrm{i}}=0$ ) maximum LIF signals and the computed peak mole fractions of PAHs. The experimental results indicate that PAH concentrations increase with increasing $R_{\mathrm{i}}$, and the rate of increase tends to be larger at higher detection wavelengths. Interestingly, the LIF signal measured at large wavelengths, especially at $500 \mathrm{~nm}$, increases non-linearly as $R_{\mathrm{i}}$ increases. The present model reproduces the observed trend that larger PAHs have higher rates of increase with increasing $R_{\mathrm{i}}$. It is known that LIF signals at higher detection wavelengths represent larger PAH molecules [44-46]. The non-linear increase at $500 \mathrm{~nm}$ is also well captured by the proposed model, wherein large PAH molecules (A4 and A5) increase nonlinearly with increasing $R_{\mathrm{i}}$.

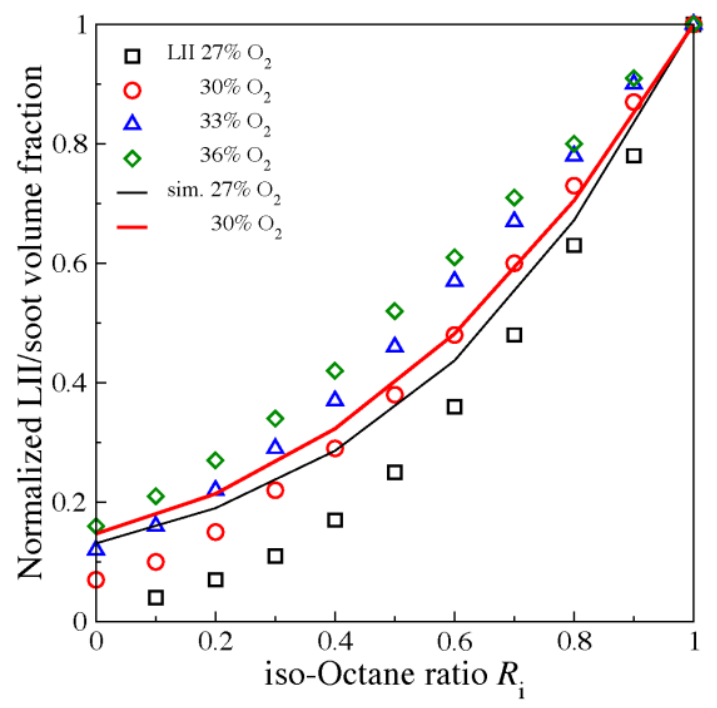

Fig. 11. Normalized LII signals and simulated soot volume fractions in the counterflow diffusion flames of $n-$ heptane/iso-octane mixtures. 
LII intensities were also measured for PRF mixtures with varying oxygen mole fraction. Figure 11 shows maximum LII signals and computed soot volume fractions normalized against data at $R_{\mathrm{i}}=1$. The LII results show that the non-liner increasing trend of LII signals is similar to LIF data at higher wavelengths shown in Fig. 10. In addition, the experimental data indicate that the non-linearity of increasing LII signals tends to be smaller at higher oxygen concentration cases.

The soot volume fractions were simulated by coupling the present mechanism with the soot model recently proposed by Wang et al. [59], which includes 36 soot nucleation reactions from 8 PAH molecules with particle surface growth from the modified HACA growth mechanism [60], PAH condensation and particle-particle coagulation. The soot model considers soot nucleation reactions including pyrene and larger PAHs since large PAHs are thought to be precursors to soot particles. Although it has been detailed in Ref [59], we still provide a brief description of the soot calculation here for reference. Soot particle growth is described via surface reactions following the formalism of Appel et al. [62] and particle coagulation occurs from the collision of two particles. Firstly, the mole fractions of the molecular soot precursors (i.e. $\mathrm{C}_{2} \mathrm{H}_{2}, \mathrm{C}_{3} \mathrm{H}_{3}, \mathrm{PAHs}$ and etc.) are calculated using the gas phase kinetic mechanism (provided in the supplementary material). Afterwards, these gas phase mole fraction profiles were used to compute the soot nucleation, PAH condensation and surface reaction rates, which are used as source term in the soot moment transport equations. The formation of soot definitely will consume some the molecular soot precursors, the amount of which can be determined from the above-mentioned source term. Therefore, after solving the soot moment equation, gas-phase species conservation equations are computed again considering these consumptions. The gas-phase and soot moment equations are solved iteratively in this fashion until convergence is obtained. Detailed soot nucleation and surface reactions along with their related rates can be found in the supplementary material of Ref. [59].

In the previous study on ethylene flames [59], collision rates for soot inception were tuned for a satisfactory agreement between the simulated and experimentally observed maximum soot volume fraction using the correction constant, $\gamma$, which represents the probability of successful creation of a new soot nucleus. The necessity of this tuning is that the collision efficiencies among PAH species for soot nucleation are temperature dependent [61], and therefore they also depend on flame conditions which have major impacts on flame temperature (i.e. fuels and dilution levels of fuel and oxidizer streams). 
In the present study, the correction constant, $\gamma$, is adjusted to be 0.00145 to match with the maximum soot volume fraction for the PRF mixture (10\% n-heptane $+90 \%$ iso-octane) at $30 \% \mathrm{O}_{2}$ condition in Fig. 3b, and the results are shown by the solid lines in Fig. 11.

The simulated soot volume fractions using this nucleation model capture the experimentally observed trend reasonably well with respect to the effects of iso-octane content and oxidizer dilution. Note that coronene (A7) concentration was reduced by maximum $13.0 \%$ with the nucleation model as compared with the gas-phase computations without having soot formation at $30 \% \mathrm{O}_{2}$ condition, while $\mathrm{A} 4$ was reduced by $3.8 \%$ at the same condition; this is because the soot model has different collision efficiencies of PAHs ranging from pyrene to coronene for soot nucleation [59]. The simulated results underestimate the effects of oxygen concentration since collision efficiencies among PAH species for soot nucleation were determined at a specified condition. Therefore, a temperature-dependent collision efficiency should be investigated for various flame conditions to account for the changes in PAH coagulation efficiencies with changing flame temperatures.

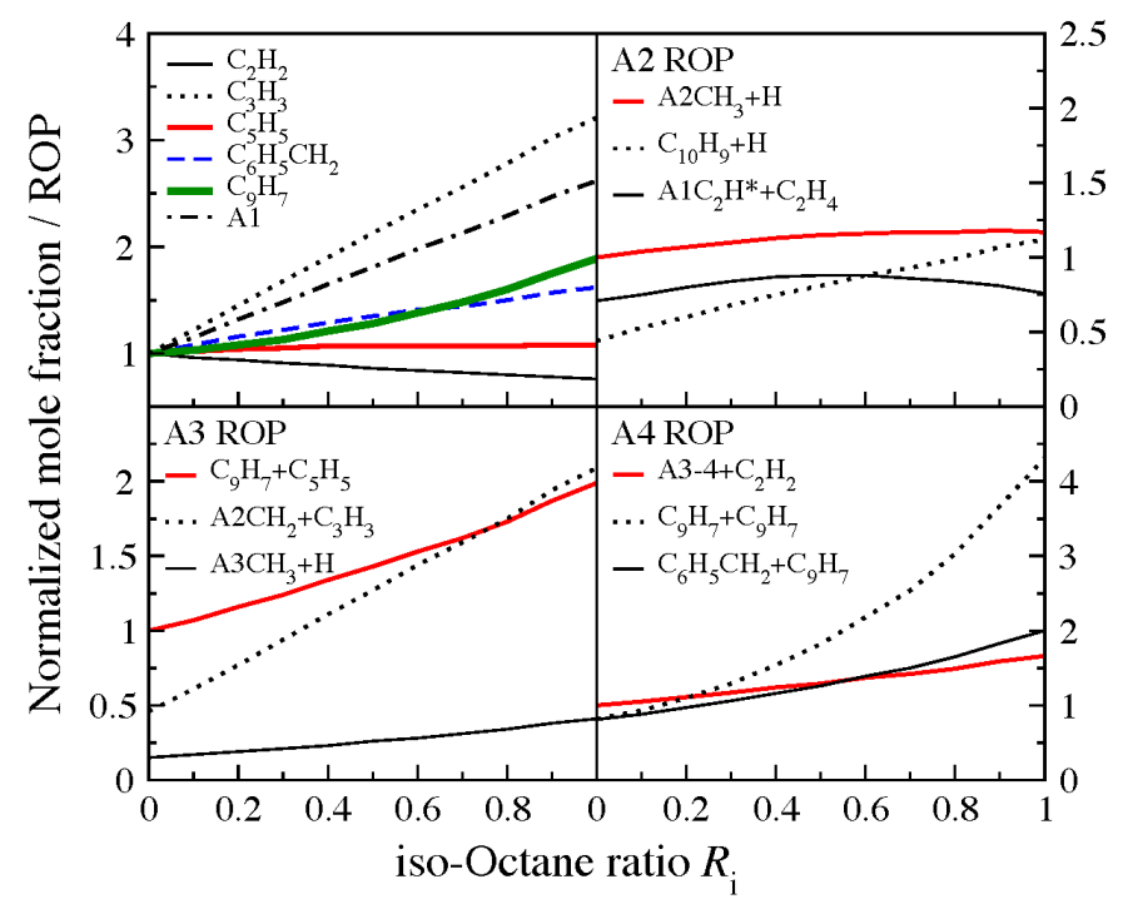

Fig. 12. Normalized maximum mole fractions of important species for PAHs formation and ROP of PAHs of n-heptane/iso-octane mixtures.

To better understand the formation of PAHs in PRF mixtures, normalized maximum mole fractions of important species involved in the formation of PAHs (A2-A4) are presented in Fig. 12. While most odd-carbon number species increase as $R_{\mathrm{i}}$ increases, cyclopentadienyl radical $\left(\mathrm{C}_{5} \mathrm{H}_{5}\right)$ is nearly unaltered. These odd-carbon number species are resonantly stabilized radicals (RSRs), which play a significant role in the formation of 
PAHs [25]. An increase of propargyl radical is prominent with increasing $R_{\mathrm{i}}$. Increasing iso-octane content in $\mathrm{n}$ heptane increases $\mathrm{C}_{3}$ species and decreases $\mathrm{C}_{2}$ species. Additionally, benzene also increases linearly, which is mainly produced from the reactions between $\mathrm{C}_{3}$ species (propargyl and allyl radicals).

Figure 12 also shows the integrated rate of production (ROP) values for PAHs (A2-A4). This was performed to avoid exaggerating reactions having the peak value in the narrow reaction zone. The formation pathways via $\mathrm{H}$ addition to aromatic radicals were not considered here to isolate the effect of other reactions. The major reactions producing $\mathrm{A} 2$ are the replacement of methyl group of 1-methylnaphthalene by $\mathrm{H}$ atom (via a hydrogen addition and beta-scission reaction, $\left.\mathrm{A} 2 \mathrm{CH}_{3}+\mathrm{H} \rightarrow \mathrm{A} 2+\mathrm{CH}_{3}\right)$, the addition of ethylene $\left(\mathrm{C}_{2} \mathrm{H}_{4}\right)$ to

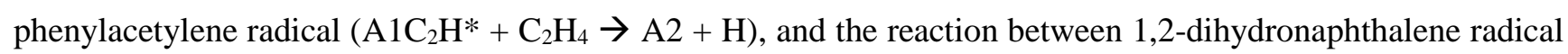
$\left(\mathrm{C}_{10} \mathrm{H}_{9}\right)$ and $\mathrm{H}$ atom $\left(\mathrm{C}_{10} \mathrm{H}_{9}+\mathrm{H} \rightarrow \mathrm{A} 2+\mathrm{H}_{2}\right)$. The former two reactions slightly increase with increasing $R_{\mathrm{i}}$ and then decrease with further increasing of $R_{\mathrm{i}}$, but the latter increases linearly as $R_{\mathrm{i}}$ increases. $\mathrm{A}_{2} \mathrm{CH}_{3}$ is mainly generated from A2 via the reaction between naphthalene and methyl radicals ( $\mathrm{A} 2-1+\mathrm{CH}_{3} \rightarrow \mathrm{A}_{2} \mathrm{CH}_{3}$ ), while phenylacetylene radical is mainly produced through reactions between phenyl $\left(\mathrm{C}_{6} \mathrm{H}_{5}\right)$ radical and acetylene $\left(\mathrm{C}_{2} \mathrm{H}_{2}\right)$. The opposing trends of benzene and acetylene could lead to the parabolic variation of A2 ROP with $R_{\mathrm{i}}$. However, the A2 formation pathway through $\mathrm{C}_{10} \mathrm{H}_{10}$ becomes important as $R_{\mathrm{i}}$ increases because $\mathrm{C}_{10} \mathrm{H}_{10}$ is mainly produced from the reaction between propargyl and benzyl radicals $\left(\mathrm{C}_{6} \mathrm{H}_{5} \mathrm{CH}_{2}+\mathrm{C}_{3} \mathrm{H}_{3} \rightarrow \mathrm{C}_{10} \mathrm{H}_{10}\right)$, i.e., both species increase linearly with increasing $R_{\mathrm{i}}$. The important pathways for A3 formation are the addition of an indenyl $\left(\mathrm{C}_{9} \mathrm{H}_{7}\right)$ radical on a cyclopentadienyl radical $\left(\mathrm{C}_{9} \mathrm{H}_{7}+\mathrm{C}_{5} \mathrm{H}_{5} \rightarrow \mathrm{A} 3+2 \mathrm{H}\right)$ and the reaction between naphtyl-methylene and propargyl radicals $\left(\mathrm{A}_{2} \mathrm{CH}_{2}+\mathrm{C}_{3} \mathrm{H}_{3} \rightarrow \mathrm{A} 3+2 \mathrm{H}\right)$ as a result of the increasing trend of propargyl and indenyl radicals with increasing $R_{\mathrm{i}}$. A4 is mainly formed by the self-addition of indenyl radicals $\left(\mathrm{C}_{9} \mathrm{H}_{7}+\mathrm{C}_{9} \mathrm{H}_{7} \rightarrow \mathrm{A} 4+\mathrm{C}_{2} \mathrm{H}_{2}+\mathrm{H}_{2}\right)$, the reaction between benzyl and indenyl radicals $\left(\mathrm{C}_{6} \mathrm{H}_{5} \mathrm{CH}_{2}+\mathrm{C}_{9} \mathrm{H}_{7} \rightarrow \mathrm{A} 4\right.$ $\left.+2 \mathrm{H}_{2}\right)$, and the addition of acetylene $\left(\mathrm{C}_{2} \mathrm{H}_{2}\right)$ on a phenanthrene radical $\left(\mathrm{A} 3-4+\mathrm{C}_{2} \mathrm{H}_{2} \rightarrow \mathrm{A} 4+\mathrm{H}\right)$. Benzyl radicals are mainly produced from the reaction of cyclopentadienyl radical with acetylene $\left(\mathrm{C}_{5} \mathrm{H}_{5}+\mathrm{C}_{2} \mathrm{H}_{2}=\right.$ $\mathrm{C}_{6} \mathrm{H}_{5} \mathrm{CH}_{2}$ ) and indenyl radicals are generated from indene via the reaction between benzyl radicals and acetylene $\left(\mathrm{C}_{6} \mathrm{H}_{5} \mathrm{CH}_{2}+\mathrm{C}_{2} \mathrm{H}_{2} \rightarrow \mathrm{C}_{9} \mathrm{H}_{8}+\mathrm{H}\right)$ or the addition of $\mathrm{C}_{3}$ species on $\mathrm{A} 1$ (or phenyl radicals) $\left(\mathrm{A} 1+\mathrm{C}_{3} \mathrm{H}_{3}\right.$ $\rightarrow \mathrm{C}_{9} \mathrm{H}_{8}+\mathrm{H}$ or $\left.\mathrm{C}_{6} \mathrm{H}_{5}+\mathrm{C}_{3} \mathrm{H}_{4}-\mathrm{A} \rightarrow \mathrm{C}_{9} \mathrm{H}_{8}+\mathrm{H}\right)$. It should be noted that the self-addition reaction of indenyl radicals shows a strong effect of non-linear increase of A4 rather than the reaction between benzyl and indenyl radicals. The indenyl radicals can be formed from either the reaction between benzyl radicals and acetylene or the addition of $\mathrm{C}_{3}$ species on $\mathrm{A} 1$ (or phenyl radical, $\mathrm{C}_{6} \mathrm{H}_{5}$ ). The peak mole fraction of indenyl radical also 
increases non-linearly with increasing $\mathrm{R}_{\mathrm{i}}$. A more detailed discussion on A4 formation for PRF mixtures is presented later. These ROP results indicate that the reactions including propargyl radicals become important to form PAHs as $R_{\mathrm{i}}$ increases. Additionally, PAH growth reactions by addition $\mathrm{C}_{2}$ and $\mathrm{C}_{3}$ species on the PAH radicals also contribute considerably to the PAH formation of PRF mixtures.

The major PAH growth pathways from A2 to A4 for n-heptane/iso-octane mixtures are presented in Fig. 13. The formation pathways via $\mathrm{H}$ addition to aromatic radicals were not considered here and some reactions involved in the formation of PAHs were also simplified to better clarify the important species. Clearly, as will be shown later, odd-carbon number species such as benzyl $\left(\mathrm{C}_{6} \mathrm{H}_{5} \mathrm{CH}_{2}\right)$ and indenyl $\left(\mathrm{C}_{9} \mathrm{H}_{7}\right)$ radicals contribute to the PAH formation in the flames of n-heptane/toluene and iso-octane/toluene mixtures.

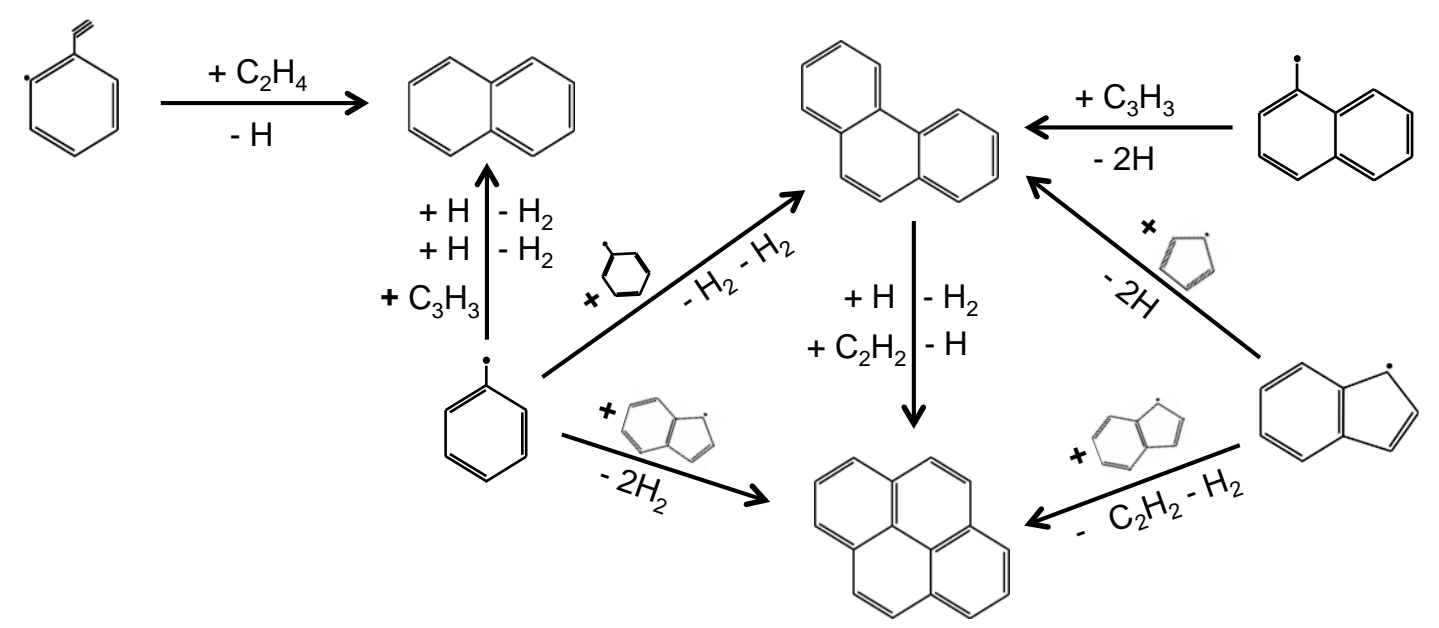

Fig. 13. Simplified major reaction pathways of the formation of PAHs (A2-A4) for n-heptane/ iso-octane mixtures.

\section{4 n-Heptane/toluene and iso-octane/toluene flames}

Following the above discussions on the effects of fuel compositions on PAH and soot formation of PRF mixtures, we now turn to the PAH and soot formation in counterflow diffusion flames of TPRF mixtures. Choi et al. [12] measured PAHs and soot for binary n-heptane/toluene and iso-octane/toluene fuels in CDF flames using LIF (detection at $400 \mathrm{~nm}$ ) and LII techniques, with a special focus on the chemical cross-linking effects from fuel mixing. In their experiments, the fuel stream was $70 \% \mathrm{~N}_{2}$ diluted and the oxidizer stream was comprised of $21 \% \mathrm{O}_{2}$ and $79 \% \mathrm{~N}_{2}$. The fuel and oxidizer flow velocities were set at $28 \mathrm{~cm} / \mathrm{s}$ and $21 \mathrm{~cm} / \mathrm{s}$, respectively. They found a synergistic effect wherein PAH LIF signals first increase and then decrease as the toluene ratio $\left(R_{\mathrm{T}}\right)$ increases, which is defined as the molar ratio of toluene in the binary mixture. They also noticed a critical toluene ratio $\left(R_{\mathrm{T}}>0.4\right)$ needed to observe soot formation under the test conditions. These 
flames are soot formation (SF) flames located on the oxidizer side of the stagnation plane and do not exhibit soot oxidation [37].

These flames were simulated using the present kinetic model and the simulated peak PAH mole fractions are compared with experimental LIF data as a function of $R_{\mathrm{T}}$ in Fig. 14, where experimental LII signals are also marked. Note, both simulated and experimental profiles are normalized at $R_{\mathrm{T}}=1$, as we are primarily interested in the relative importance of fuel compositions.

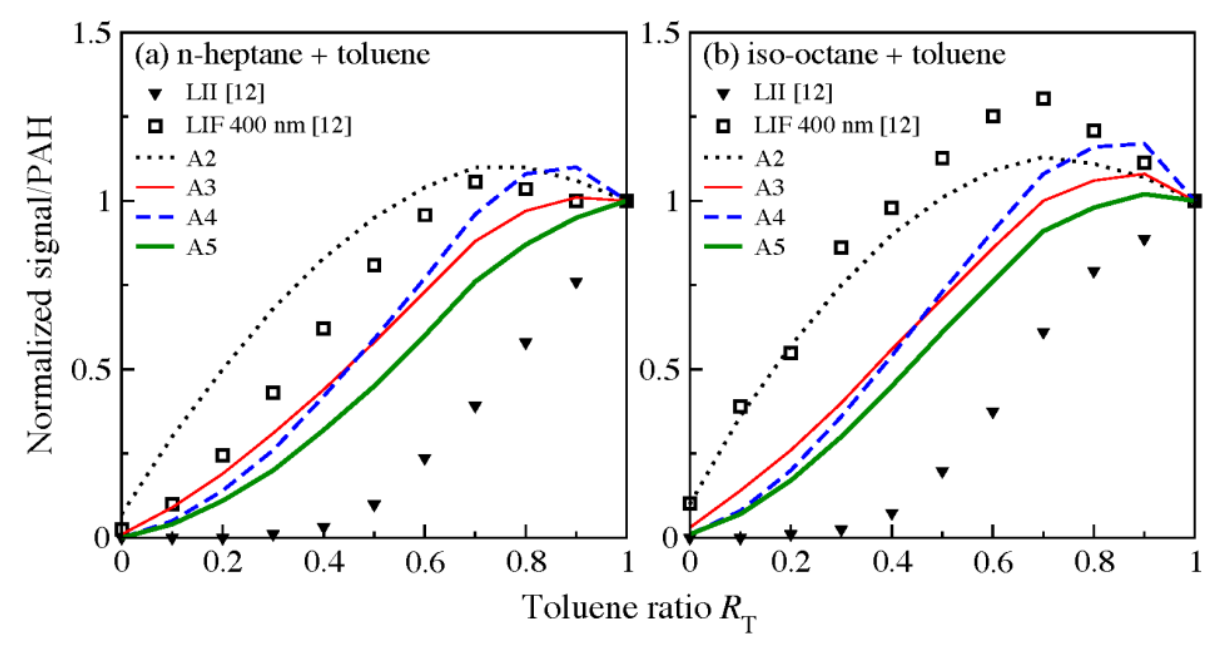

Fig. 14. Normalized LIF and LII signals [12] and simulated PAH mole fractions in the counterflow diffusion flames of n-heptane/toluene and iso-octane/toluene mixtures.

The experimental results in Fig. 14 indicate that PAHs initially increase with increasing $R_{\mathrm{T}}$, and then decrease (synergistic behavior) with further increasing of $R_{\mathrm{T}}$. In contrast, soot formation increases monotonically in the n-heptane/toluene and iso-octane/toluene mixture flames at the given conditions. The reported LIF data measured at $400 \mathrm{~nm}$ is expected to be contributed primarily by A2 and A4, since 1) these PAHs exhibit maximum fluorescence intensities and have longest-lifetime near $400 \mathrm{~nm}$ under high temperature and concentration conditions [63]; 2) in these counterflow diffusion flames A2 and A4 have much higher concentration as compared to A5 (confirmed from computed mole fractions). Having this in mind, we see that the present model captures the synergistic effect of PAHs (A2 and A4) in both sets of diffusion flames, with A2 being closest to LIF data. Note, the LIF data at $400 \mathrm{~nm}$ can imply the involvement of several PAHs due to the broad excitation and emission characteristics of PAHs.. The profiles of larger PAH molecules (e.g., A5) tend to approach those of LII signals representing soot volume fractions. This similarity indicates that larger PAHs contribute appreciably to the inception and growth of soot particles, consistent with previous studies [25, 31]. 


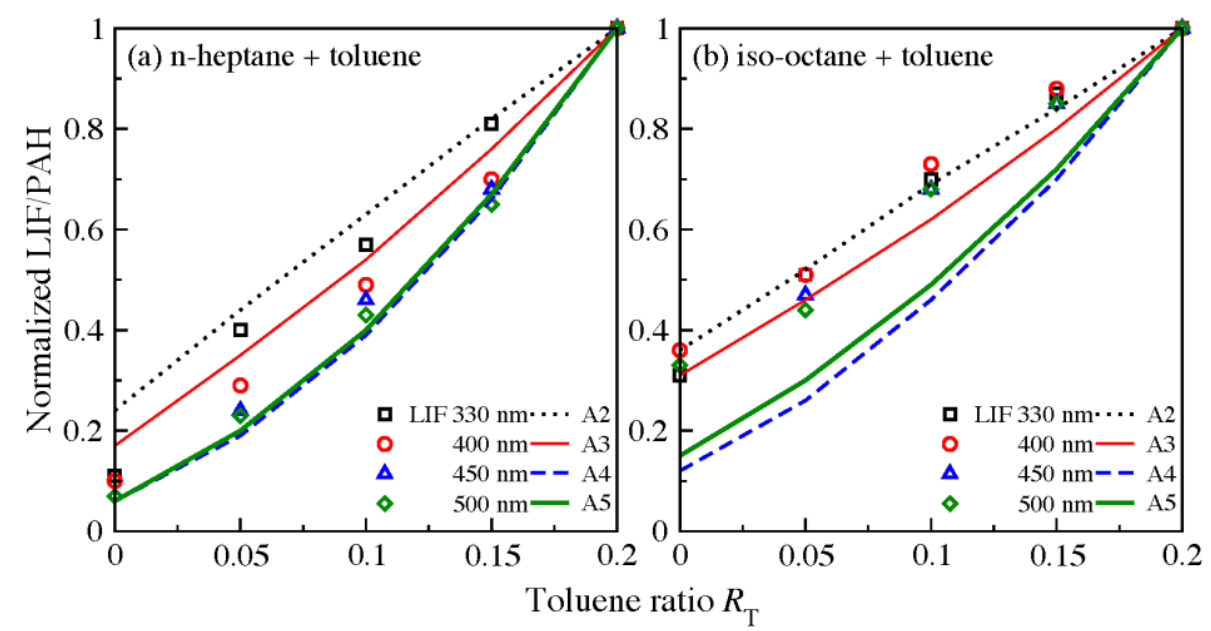

Fig. 15. Normalized LIF signals and simulated PAH mole fractions in the counterflow diffusion flames of nheptane/toluene and iso-octane/toluene mixtures.

In the previous study [12], the flames are non-sooting when $R_{\mathrm{T}}$ is below $0.2-0.3$ (as can be seen from the peak LII signals) and the broadband PAH LIF were detected only at one wavelength (400nm). In order to more comprehensively describe the formation characteristics of different sized PAH species with toluene addition to n-heptane and iso-octane, new experiments were designed to have soot formation even when $R_{\mathrm{T}}<$ 0.2. This was achieved by using less $\mathrm{N}_{2}$ dilution $\left(X_{\mathrm{F}}=65 \%\right)$ and strain $\left(V_{0}=20 \mathrm{~cm} / \mathrm{s}\right)$ as compared to the conditions in [12]. PAHs were detected via LIF using various detection wavelengths by varying the toluene ratio $\left(R_{\mathrm{T}}\right)$. The new experimental results shown in Figs. $15 \mathrm{a}$ and $15 \mathrm{~b}$ (normalized by data at $R_{\mathrm{T}}=0.2$ ) indicates that toluene addition has a stronger effect on the formation of PAHs when added to n-heptane as compared to iso-octane (i.e., based on the slopes), especially for small detection wavelength corresponding to small size PAHs. In n-heptane/toluene mixtures, the LIF signal at higher wavelengths increases non-linearly as $R_{\mathrm{T}}$ increases and the model reproduces this behavior. The simulated maximum mole fractions of larger PAHs (A4 and benzo[e]pyrene, A5) are close to the LIF signal detected at $500 \mathrm{~nm}$. Note, the observed LIF signals can imply the involvement of several PAHs due to the broad excitation and emission characteristics of PAHs, and therefore direct comparison of individual PAHs are rather limited. On the contrary, LIF signals in isooctane/toluene mixtures up to $R_{\mathrm{T}}=0.2$ increase reasonably linearly regardless of detection wavelengths. The simulated PAHs (A2 and phenanthrene, A3) for iso-octane/toluene mixtures show similar behavior with LIF data, while larger PAHs (A4 and A5) do not capture this behavior. 


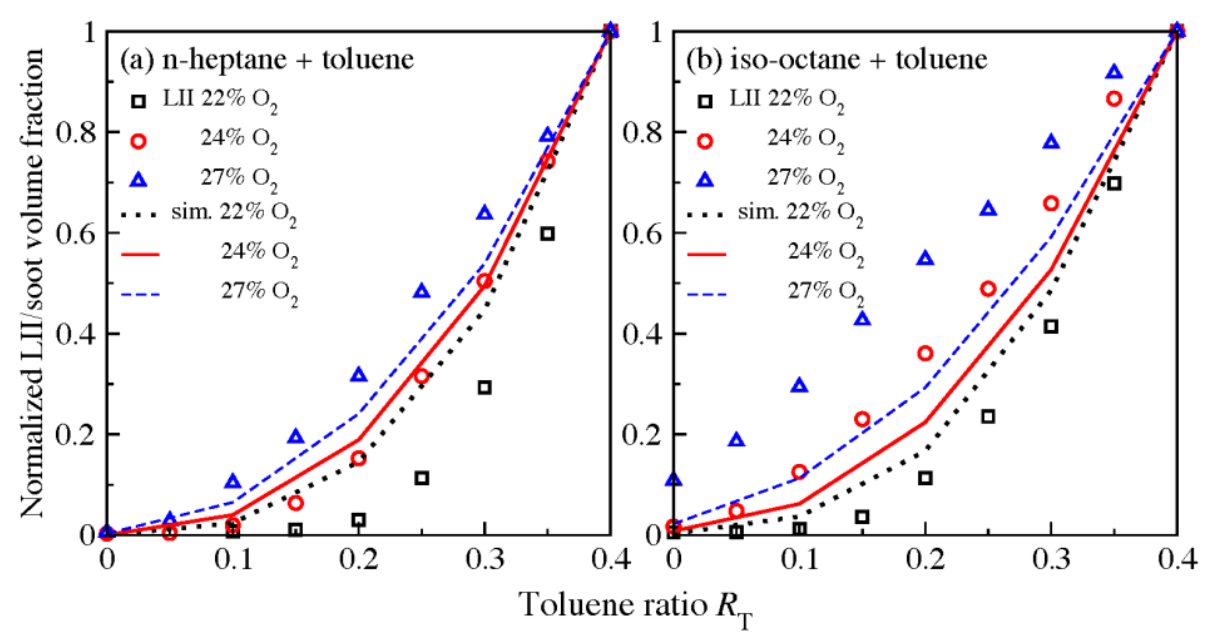

Fig. 16. Normalized LII signals and simulated soot volume fractions in the counterflow diffusion flames of nheptane/toluene and iso-octane/toluene mixtures.

LII intensities were measured for the binary n-heptane/toluene and iso-octane/toluene mixtures up to $R_{\mathrm{T}}=0.4$ with varying oxygen mole fraction to provide a better understanding the effect of toluene addition on soot formation. Figure 16 shows maximum LII signals and computed soot volume fractions normalized against data at $R_{\mathrm{T}}=0.4$. The experimental data show that the increasing trend of LII signals with increasing $R_{\mathrm{T}}$, measured at $24 \% \mathrm{O}_{2}$ condition, are similar to the trend in LIF signals detected at higher wavelengths in Fig. 15. This is expected because larger PAH species (A5-A7), which are represented by LIF signals at higher detection wavelengths, are important soot precursors [58]. In n-heptane/toluene mixtures, the LII signal increases nonlinearly with increasing $R_{\text {T. }}$. The LII signals in iso-octane/toluene mixtures also show such non-linear increasing behavior, while at large oxygen concentration case ( $27 \%$ oxygen), the LII signal increases reasonably linearly. This emphasize the effect of initial oxygen mole fraction, through which the flame temperature and flame position relative to the stagnation plane are influenced, on soot formation. The experimental results also show that soot formation in iso-octane/toluene flames is relatively more responsive to increasing $\mathrm{O}_{2}$ concentration as compared to n-heptane/toluene flames.

Here the simulation was conducted with the reduced nucleation model, since the dispersed phase calculation tends to over-estimate surface consumption rates of some PAH species, especially for heavily sooting flames. The simulated soot volume fractions using the reduced nucleation model reproduce the experimentally observed increasing trend and the qualitative effect of $\mathrm{O}_{2}$ concentration on soot formation in both n-heptane/toluene and iso-octane/toluene flames. However, the simulated soot volume fractions do not capture the significant increase observed for iso-octane/toluene mixtures when the $\mathrm{O}_{2}$ concentration increases to $27 \%$ quantitatively. Further improvements, especially an accurate and experimentally validated expression of temperature- 
effects of $\mathrm{O} 2$ concentration on $\mathrm{PAH}$ formation of iso-octane/toluene mixtures.

Furthermore, the synergistic effects observed by Choi et al. [12] and shown in Fig. 14 along with those in Fig. 15 for PAHs are rather interesting and deserve further investigations.

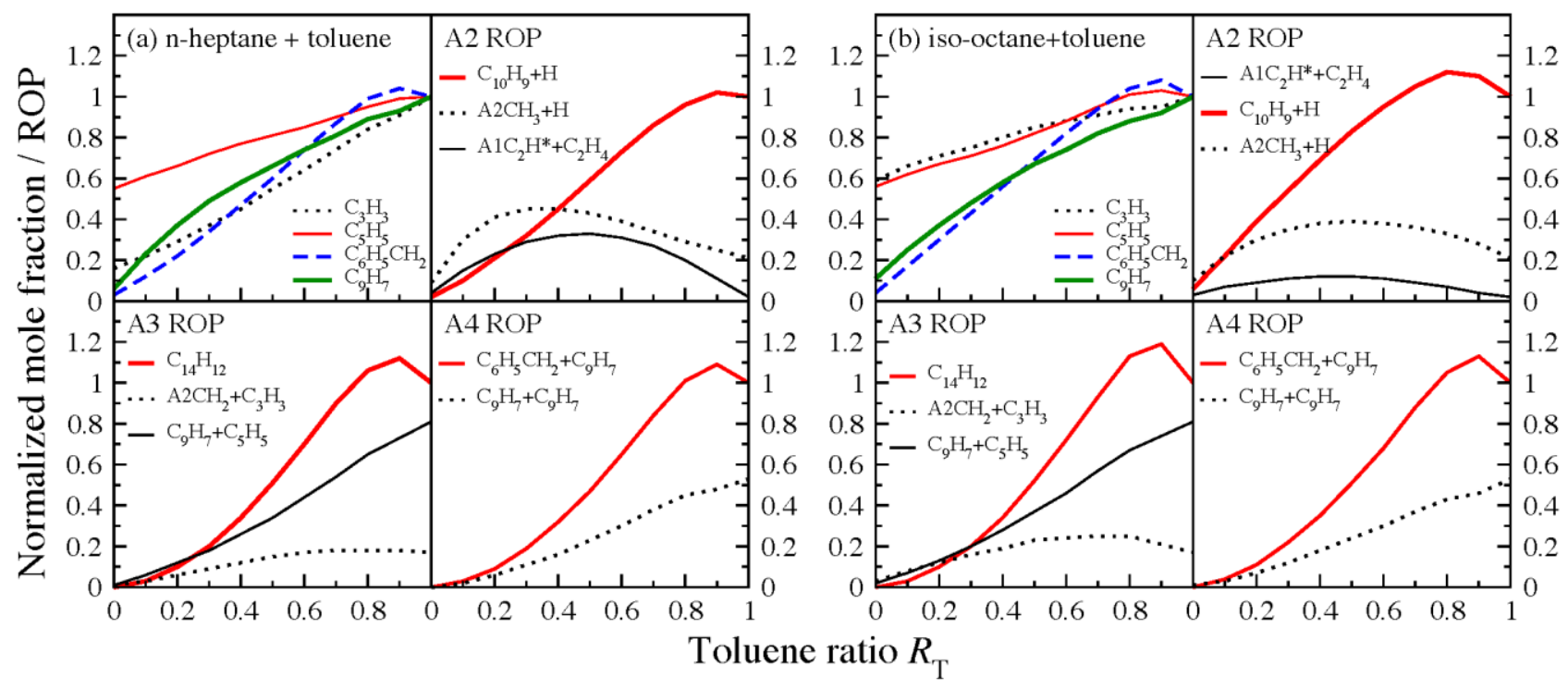

Fig. 17. Normalized maximum mole fractions of odd-carbon number species and ROP of PAHs of n-heptane/toluene and iso-octane/toluene mixtures.

To better understand the chemical cross-linking effect of the binary mixtures containing toluene, peak mole fractions of odd-carbon number species $\left(\mathrm{C}_{3} \mathrm{H}_{3}, \mathrm{C}_{5} \mathrm{H}_{5}, \mathrm{C}_{6} \mathrm{H}_{5} \mathrm{CH}_{2}\right.$ and $\left.\mathrm{C}_{9} \mathrm{H}_{7}\right)$ and major reaction pathways for A2A4 productions are presented in Fig. 17. All peak mole fractions are scaled against those of the pure toluene flame. The integrated ROP values for PAHs are scaled against the reaction having maximum ROP at $R_{\mathrm{T}}=1$.

For n-heptane/toluene mixtures, the peak mole fractions of odd-carbon number species increase monotonically as $R_{\mathrm{T}}$ increases, except for benzyl $\left(\mathrm{C}_{6} \mathrm{H}_{5} \mathrm{CH}_{2}\right)$ radicals, which exhibit synergistic behavior (having maximum near $R_{\mathrm{T}}=0.8-0.9$ ). Benzyl radicals are mainly formed from toluene dehydrogenation and slightly increase as n-heptane is added to pure toluene. Despite the slight decrease of toluene content at $R_{\mathrm{T}}=0.8$ 0.9, the increased radicals $\left(\mathrm{H}\right.$ and $\left.\mathrm{CH}_{3}\right)$ produced from n-heptane can enhance the production of benzyl radicals by $\mathrm{H}$-atom abstraction reactions from toluene. Important PAH formation pathways from ROP analysis are shown in Fig. 17. A2 is mainly formed by $\mathrm{A} 2 \mathrm{CH}_{3}+\mathrm{H} \rightarrow \mathrm{A} 2+\mathrm{CH}_{3}, \mathrm{~A}_{1} \mathrm{C}_{2} \mathrm{H}^{*}+\mathrm{C}_{2} \mathrm{H}_{4} \rightarrow \mathrm{A} 2+\mathrm{H}$, and $\mathrm{C}_{10} \mathrm{H}_{9}+$ $\mathrm{H} \rightarrow \mathrm{A} 2+\mathrm{H}_{2}$. The latter is the most dominant pathway to A2 since $\mathrm{C}_{10} \mathrm{H}_{9}$ is produced from $\mathrm{C}_{10} \mathrm{H}_{10}$, which 
comes from the reaction between benzyl and propargyl radicals. The important pathways for A3 formation are from cis-stilbene $\left(\mathrm{C}_{14} \mathrm{H}_{12} \rightarrow \mathrm{A} 3+\mathrm{H}_{2}\right)$, which is produced from bibenzyl $\left(\mathrm{C}_{14} \mathrm{H}_{14}\right)$ via the self-addition of benzyl radicals, and the addition of an indenyl $\left(\mathrm{C}_{9} \mathrm{H}_{7}\right)$ radical on a cyclopentadienyl radical $\left(\mathrm{C}_{9} \mathrm{H}_{7}+\mathrm{C}_{5} \mathrm{H}_{5} \rightarrow \mathrm{A} 3+2 \mathrm{H}\right)$. The former is a dominant pathway for n-heptane/toluene diffusion flames. A4 is mainly formed by $\mathrm{C}_{6} \mathrm{H}_{5} \mathrm{CH}_{2}+$ $\mathrm{C}_{9} \mathrm{H}_{7} \rightarrow \mathrm{A} 4+2 \mathrm{H}_{2}$ and $\mathrm{C}_{9} \mathrm{H}_{7}+\mathrm{C}_{9} \mathrm{H}_{7} \rightarrow \mathrm{A} 4+\mathrm{C}_{2} \mathrm{H}_{2}+\mathrm{H}_{2}$. The reaction of benzyl radical with indenyl radicals is a dominant pathway to generate A4.

The ROP results indicate that the synergistic effect of PAHs with varying $R_{\mathrm{T}}$ mainly results from the reactions involving benzyl radicals. As expected, the odd-carbon numbered species are actively involved in the formation of PAHs, and reactions including benzyl radicals are the dominant pathways to produce PAHs for nheptane/toluene mixtures. Similar behaviors have been observed for iso-octane/toluene mixtures (Fig. 17b). One exception is the synergistic behavior for cyclopentadienyl $\left(\mathrm{C}_{5} \mathrm{H}_{5}\right)$ profiles; this species is mainly formed by the benzyl radical decomposition $\left(\mathrm{C}_{6} \mathrm{H}_{5} \mathrm{CH}_{2}=\mathrm{C}_{5} \mathrm{H}_{5}+\mathrm{C}_{2} \mathrm{H}_{2}\right)$ at higher $R_{\mathrm{T}}$ and the relatively large synergistic effect of benzyl radical in iso-octane/toluene mixtures can lead to the slight increase of $\mathrm{C}_{5} \mathrm{H}_{5}$ at $R_{\mathrm{T}}=0.9$.

\section{5 n-Heptane/iso-octane/toluene flames}

Following the analysis of the compositional effects on PAH and soot formation for binary PRF mixtures, we next focus on the ternary TPRF mixtures (n-heptane, iso-octane and toluene). First, PAH LIF signals were measured at different wavelengths for TPRF mixtures to study PAH formation. During these experiments, the amount of toluene added is fixed at 10\% (T10PRF) or 20\% (T20PRF), while the remaining proportion was comprised of iso-octane and $\mathrm{n}$-heptane mixtures with varying iso-octane molar ratios $\left(R_{\mathrm{i}}\right)$ among $\mathrm{n}$-heptane and iso-octane, ranging from $\mathrm{n}$-heptane/toluene $\left(R_{\mathrm{i}}=0\right)$ to iso-octane/toluene $\left(R_{\mathrm{i}}=1\right)$ mixtures. 


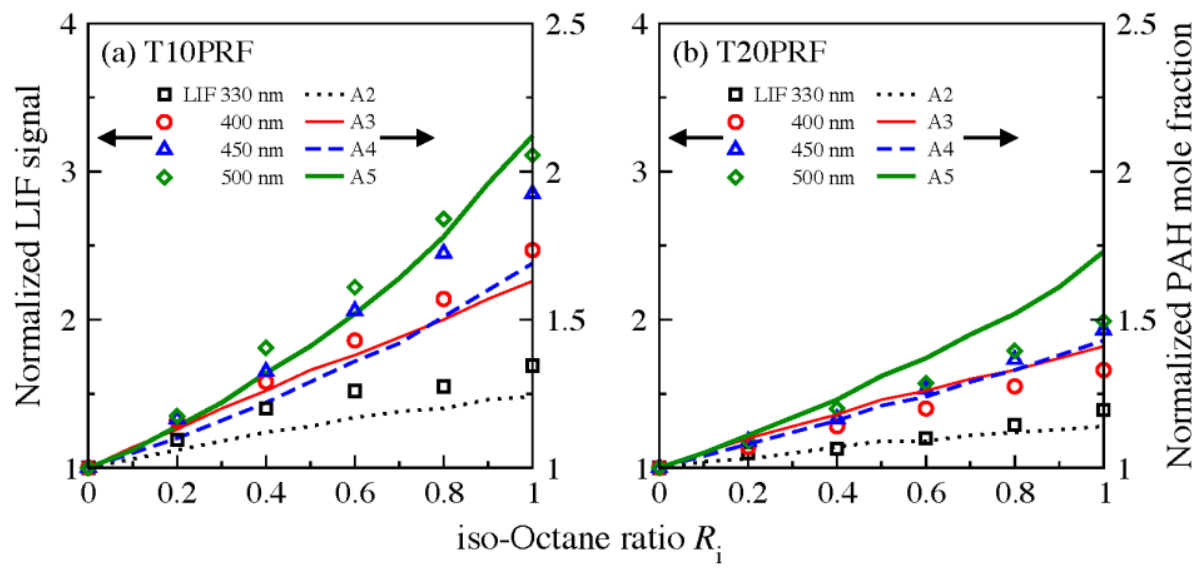

Fig. 18. Normalized maximum LIF signals and computed PAHs for n-heptane/iso-octane/toluene mixtures in SF conditions.

Figure 18 shows the normalized maximum LIF signals and computed mole fractions of PAHs in terms of isooctane ratio $\left(R_{\mathrm{i}}\right)$ in the TPRF mixtures. LIF intensities and peak mole fractions of PAHs are scaled against those of the $\mathrm{n}$-heptane/toluene flame $\left(R_{\mathrm{i}}=0\right)$. The experimental results indicate that the PAH formation trend for TPRF mixtures is similar to PRF mixtures, wherein PAHs increase at different rates at various detection wave lengths with varying $R_{\mathrm{i}}$. Note that the LIF signals measured at various wavelengths increase reasonably linearly for both the T10PRF and T20PRF mixtures, which is different from PRF mixtures. As was shown in Fig. 10 of the PRF mixtures, the LIF data for shorter detection wave length $(330 \mathrm{~nm})$ was reasonably linear while at longer wave length, the LIF data showed nonlinear increasing behavior with $R_{\mathrm{i}}$. The results in Fig. 18 also show that as $R_{\mathrm{i}}$ increases, the rate of PAH increase in T10PRF mixtures is larger than in T20PRF mixtures. The predicted PAHs (A2-A5) well capture this observed trend of the linear increase of LIF signals, although the A5 prediction exhibits slightly nonlinear behavior with $R_{\mathrm{i}}$.

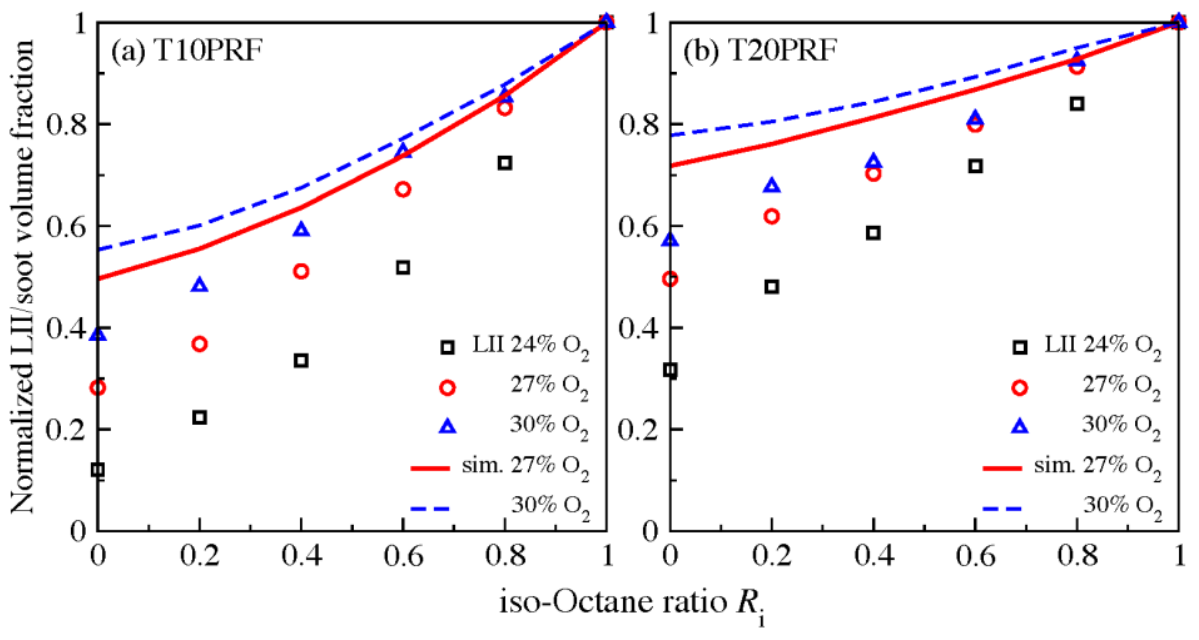


Fig. 19. Normalized LII signals and simulated soot volume fractions in the counterflow diffusion flames of nheptane/iso-octane/toluene mixtures.

In addition, LII intensities were measured for the TPRF mixtures with iso-octane ratio at several oxygen mole fractions. Figure 19 shows the maximum LII signals and computed soot volume fractions (with the reduced nucleation model) normalized at $R_{\mathrm{i}}=1$. The experimental results show that the LII signal increases reasonably linearly and the increasing rate in T10PRF mixtures is larger than in T20PRF mixtures, as LIF data in Fig. 18. The results also show that the rate of soot increase in higher $\mathrm{O}_{2}$ concentration is smaller than lower $\mathrm{O}_{2}$ conditions. This result implies that as the $\mathrm{O}_{2}$ mole fraction increases (resulting in higher flame temperature and thereby higher sooting propensity), the sensitivity of soot formation to n-heptane/iso-octane ratio diminishes. This is also true by comparing the T10PRF and T20PRF cases that as the toluene percentage increases (having higher soot propensity by adding toluene), the sensitivity diminishes. The simulated soot volume fractions reasonably reproduce the experimentally observed behavior; however, the increasing trend of soot volume fraction to iso-octane ratio is somewhat less sensitive compared to the experiment.

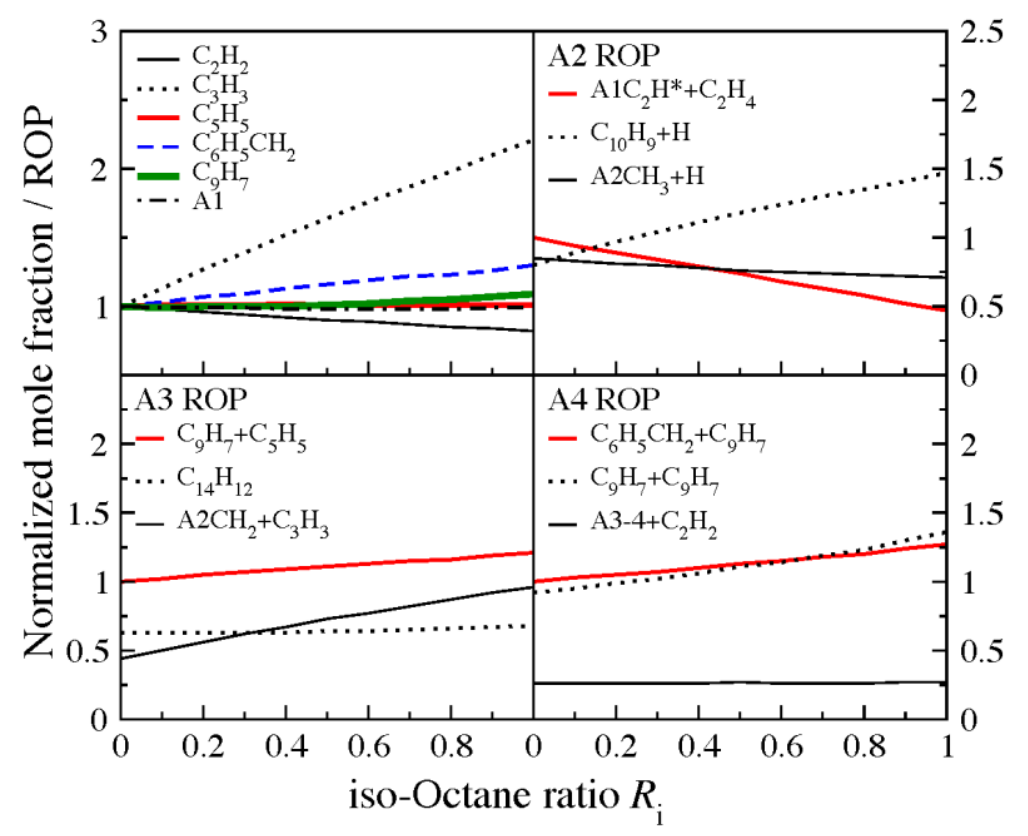

Fig. 20. Normalized maximum mole fractions of major species for PAHs formation and ROP of PAHs of T20PRF mixtures.

Figure 20 shows normalized maximum mole fractions of major species involving the formation and growth of PAHs (A2-A4) in T20PRF mixtures. The results show that odd-carbon number species and A1 are unaltered regardless of $\mathrm{R}_{\mathrm{i}}$, except for propargyl radical, which is in contrast to PRF mixtures. Although propargyl radical increases with increasing $R_{i}$, the peak mole fraction of benzene is unchanged since benzene in TPRF mixtures is 
mainly produced from the reaction of toluene with $\mathrm{H}$ radical $\left(\mathrm{C}_{6} \mathrm{H}_{5} \mathrm{CH}_{3}+\mathrm{H}=\mathrm{C}_{6} \mathrm{H}_{6}+\mathrm{CH}_{3}\right)$. The reactions including benzyl radicals are dominant pathways to produce PAHs as discussed in the previous section (4.1). The benzyl radical formed from toluene dehydrogenation plays a significant role in PAH formation via its reaction with propargyl $\left(\mathrm{C}_{3} \mathrm{H}_{3}\right)$ radicals $\left(\mathrm{C}_{6} \mathrm{H}_{5} \mathrm{CH}_{2}+\mathrm{C}_{3} \mathrm{H}_{3} \rightarrow \mathrm{C}_{10} \mathrm{H}_{10}\right)$ to form A2, the self-addition reaction $\left(\mathrm{C}_{6} \mathrm{H}_{5} \mathrm{CH}_{2}+\mathrm{C}_{6} \mathrm{H}_{5} \mathrm{CH}_{2} \rightarrow \mathrm{C}_{14} \mathrm{H}_{14}\right)$ to form $\mathrm{A} 3$, and the reaction with indenyl radical $\left(\mathrm{C}_{6} \mathrm{H}_{5} \mathrm{CH}_{2}+\mathrm{C}_{9} \mathrm{H}_{7} \rightarrow \mathrm{A} 4+\right.$ $2 \mathrm{H}_{2}$ ) to form A4. However, the reactions involving propargyl radicals lead to the increasing trend of PAHs for T20PRF mixtures. A2 formation from the reaction between benzyl and propargyl radicals becomes important as $R_{\mathrm{i}}$ increases. The reaction $\mathrm{A} 2 \mathrm{CH}_{2}+\mathrm{C}_{3} \mathrm{H}_{3} \rightarrow \mathrm{A} 3+2 \mathrm{H}$ also becomes important for A3 formation, as well as the reaction $\mathrm{C}_{9} \mathrm{H}_{7}+\mathrm{C}_{5} \mathrm{H}_{5} \rightarrow \mathrm{A} 3+2 \mathrm{H}$. Interestingly, the maximum mole fraction of indenyl radical is unchanged regardless of $R_{\mathrm{i}}$, and the ROP of the self-addition of indenyl radicals $\left(\mathrm{C}_{9} \mathrm{H}_{7}+\mathrm{C}_{9} \mathrm{H}_{7} \rightarrow \mathrm{A} 4+\mathrm{C}_{2} \mathrm{H}_{2}+\mathrm{H}_{2}\right)$ increases linearly. This is in contrast to PRF mixtures wherein the indenyl radical and the self-addition reaction increase non-linearly with increasing $R_{\mathrm{i}}$.

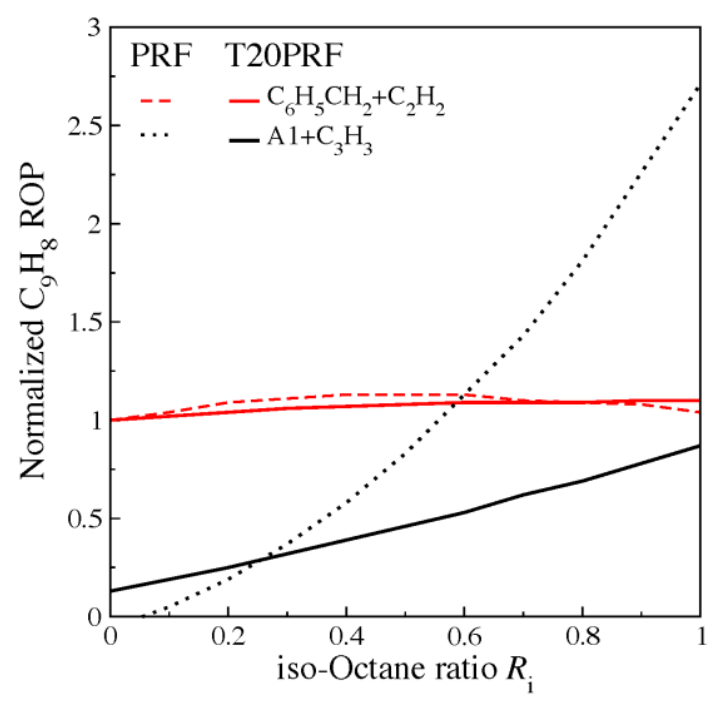

Fig. 21. Comparison of $\mathrm{C}_{9} \mathrm{H}_{8}$ ROP between PRF and T20PRF mixtures.

In order to better understand the different behavior of A4 formation between PRF and TPRF mixtures with varying $R_{\mathrm{i}}$, the $\mathrm{ROP}$ of indene $\left(\mathrm{C}_{9} \mathrm{H}_{8}\right)$ is presented in Fig. 21. The indenyl radical formation rate, which is mainly generated from indene, can rationalize variations in the trends of A4 for PRF and TPRF mixtures. As discussed previously, the non-linear increase of indenyl radical and the self-addition reaction lead to non-linear increase in A4 for the PRF mixtures, but this non-linear trend is not observed for indenyl radical in the TPRF mixtures. Indene can be produced from the reaction between benzyl radicals and acetylene $\left(\mathrm{C}_{6} \mathrm{H}_{5} \mathrm{CH}_{2}+\mathrm{C}_{2} \mathrm{H}_{2} \rightarrow\right.$ 
$\mathrm{C}_{9} \mathrm{H}_{8}+\mathrm{H}$ ) or through the addition of $\mathrm{C}_{3}$ species on $\mathrm{A} 1$ (or phenyl radicals) (A1 $+\mathrm{C}_{3} \mathrm{H}_{3} \rightarrow \mathrm{C}_{9} \mathrm{H}_{8}+\mathrm{H}_{\text {or }} \mathrm{C}_{6} \mathrm{H}_{5}+$ $\left.\mathrm{C}_{3} \mathrm{H}_{4}-\mathrm{A} \rightarrow \mathrm{C}_{9} \mathrm{H}_{8}+\mathrm{H}\right)$. Figure 21 indicates that the indene formation through benzyl radical is unchanged for both PRF and TPRF mixtures regardless of $R_{\mathrm{i}}$. However, the propargyl addition reaction to benzene increases with increasing $R_{\mathrm{i}}$ and shows the non-linear increase for PRF mixtures, which can lead to the non-linear increase of A4. Benzene is mainly formed from the recombination of $\mathrm{C}_{3}$ species in PRF mixtures, while the reaction of toluene with $\mathrm{H}$ radical is the dominant formation pathway in TPRF mixtures. Therefore, the large increase in $\mathrm{C}_{3}$ species in PRF mixtures as $R_{\mathrm{i}}$ increases leads to the non-linear increase of indene. Propargyl radicals are formed in larger quantities from branched alkanes, such as iso-octane, due to the presence of tertiary carbon sites, which favor formation of propene, allyl, and propyne [64, 65]. The unchanged benzene concentrations in TPRF mixtures can restrict the increase of indene to some extent. These results indicate that fuel components can significantly alter PAH formation pathways in gasoline surrogate fuels.

\section{Conclusions}

This study provided a detailed understanding of the relationship between gasoline surrogate fuel composition and $\mathrm{PAH} /$ soot formation processes. An updated comprehensive kinetic model for gasoline surrogates was developed to improve the prediction of the concentrations of PAHs. To better understand the cross-linking effects in various fuel mixtures, new experiments were conducted in soot formation counterflow diffusion flames for gasoline surrogate mixtures comprising n-heptane, iso-octane, and toluene.

The proposed model captures the synergistic effect observed experimentally in counterflow flames of nheptane/toluene and iso-octane/toluene mixtures. The ROP analysis indicates that benzyl radicals produced from toluene dehydrogenation are strongly related to the synergistic effect on PAH concentrations. New experimental results for PRF mixtures indicate that the LIF signal measured at $500 \mathrm{~nm}$, which represents larger PAHs, increases non-linearly as LII signal with increasing iso-octane ratio. In contrast, the $500 \mathrm{~nm}$ LIF signal increases linearly when toluene is added to PRF mixtures. The model well reproduces this trend and the ROP analysis attributes different indene formation pathways to the different behavior in PRF and TPRF mixtures. Reactions including propargyl radicals become important for the formation of PAHs as iso-octane content increases in PRF mixtures, but PAHs of TPRF mixtures are mostly produced from benzyl radicals when toluene content is high enough. These results indicate molecular structures of fuel components can significantly 
contribute to the different trends in PAH formation for gasoline surrogate fuels. The comprehensive chemical kinetic model presented herein can be used to study the impacts of gasoline surrogate fuel formulation on a range of combustion phenomenon (e.g., ignition, flame propagation, soot formation, etc.) at engine-relevant temperatures and pressures.

\section{Acknowledgment}

This work was supported by Competitive Research Funding from the King Abdullah University of Science and Technology (KAUST) and the Clean Combustion Research Center. We also acknowledge funding from Saudi Aramco R\&DC under the FUELCOM research program.

\section{References}

[1] G. Blanquart, P. Pepiot-Desjardins, H. Pitsch, Chemical mechanism for high temperature combustion of engine relevant fuels with emphasis on soot precursors, Combust. Flame 156 (2009) 588-607.

[2] F. Battin-Leclerc, Detailed chemical kinetic models for the low-temperature combustion of hydrocarbons with application to gasoline and diesel fuel surrogates, Prog. Energ. Combust. Sci. 34 (2008) 440-498.

[3] T. Bieleveld, A. Frassoldati, A. Cuoci, T. Faravelli, E. Ranzi, U. Niemann, K. Seshadri, Experimental and kinetic modeling study of combustion of gasoline, its surrogates and components in laminar non-premixed flows, Proc. Combust. Inst. 32 (2009) 493-500.

[4] A.T. Holley, Y. Dong, M.G. Andac, F.N. Egolfopoulos, Extinction of premixed flames of practical liquid fuels: Experiments and simulations, Combust. Flame 144 (2006) 448-460.

[5] S.M. Sarathy, G. Kukkadapu, M. Mehl, W. Wang, T. Javed, S. Park, M.A. Oehlschlaeger, A. Farooq, W.J. Pitz, C.-J. Sung, Ignition of alkane-rich FACE gasoline fuels and their surrogate mixtures, Proc. Combust. Inst. 35 (2015) 249-257.

[6] S.M. Sarathy, G. Kukkadapu, M. Mehl, T. Javed, A. Ahmed, N. Naser, A. Tekawade, G. Kosiba, M. Alabbad, E. Singh, S. Park, M. Al Rashidi, S.H. Chung, W.L. Roberts, M.A. Oehlschlaeger, C.-J. Sung, A. Farooq, Compositional effects on the ignition of FACE gasolines, Combust. Flame 169 (2016) 171-193.

[7] B.M. Gauthier, D.F. Daivdson, R.K. Hanson, Shock tube determination of ignition delay times in full-blend and surrogate fuel mixtures, Combust. Flame 139 (2004) 300-311.

[8] J.A. Badra, N. Bokhumseen, N. Mulla, S.M. Sarathy, A. Farooq, G. Kalghatgi, P. Gaillard, A methodology to relate octane numbers of binary and ternary n-heptane, iso-octane and toluene mixtures with simulated ignition delay times, Fuel 160 (2015) 458-469.

[9] G. Kalghatgi, H. Babiker, J.A. Badra, A Simple Method to Predict Knock Using Toluene, N-Heptane and Iso-Octane Blends (TPRF) as Gasoline Surrogates, SAE Int. J. Engines 8 (2015) 505-519.

[10] H. Wang, Formation of nascent soot and other condensed-phase materials in flames, Proc. Combust. Inst. 33 (2011) 41-67. 
[11] F. Inal, S.M. Senkan, Effects of equivalence ratio on species and soot concentrations in premixed nheptane flames, Combust. Flame 131 (2002) 16-28.

[12] B.C. Choi, S.K. Choi, S.H. Chung, Soot formation characteristics of gasoline surrogate fuels in counterflow diffusion flames, Proc. Combust. Inst. 33 (2011) 609-616.

[13] J.Y. Hwang, W. Lee, G.G. Kang, S.H. Chung, Synergistic effect of ethylene-propane mixture on soot formation in laminar diffusion flames, Combust. Flame 114 (1998) 370-380.

[14] S.S.Yoon, S.M. Lee, S.H. Chung, Effect of mixing methane, ethane, propane and propene on the synergistic effect of PAH and soot formation in ethylene-base counterflow diffusion flames, Proc. Combust. Inst. 30 (2005) 1417-1424.

[15] S.S. Yoon, D.H. Ahn, S.H. Chung, Synergistic effect of mixing dimethyl ether with methane, ethane, propane, and ethylene fuels on polycyclic aromatic hydrocarbon and soot formation, Combust. Flame 154 (2008) 368-377.

[16] M. Kashif, P. Guibert, J. Bonnety, G. Legros, Sooting tendencies of primary reference fuels in atmospheric laminar diffusion flames burning into vitiated air, Combust. Flame 161 (2014) 1575-1586.

[17] J.-L. Consalvi, F. Liu, J. Contreras, M. Kashif, G. Legros, S. Shuai, J. Wang, Numerical study of soot formation in laminar coflow diffusion flames of methane doped with primary reference fuels, Combust. Flame 162 (2015) 1153-1163.

[18] M.Kashif, J. Bonnety, A. Matynia, P. Da Costa, G. Legros, Sooting propensities of some gasoline surrogate fuels: Combined effects of fuel blending and air vitiation, Combust. Flame 162 (2015) 1840-1847.

[19] Y. Li, J. Cai, L. Zhang, T. Yuan, K. Zhang, F. Qi, Investigation on chemical structures of premixed toluene flames at low pressure, Proc. Combust. Inst. 33 (2011) 593-600.

[20] A. D'Anna, A. Ciajolo, M. Alfe, B. Apicella, A. Tregrossi, Effect of fuel/air ratio and aromaticity on the molecular weight distribution of soot in premixed n-heptane flames, Proc. Combust. Inst. 32 (2009) 803-810.

[21] S. Mosbach, M.S. Celnik, A. Raj, M. Kraft, H.R. Zhang, S. Kubo, K.-O. Kim, Towards a detailed soot model for internal combustion engines, Combust. Flame 156 (2009) 1156-1165.

[22] C. Marchal, J.-L. Delfau, C. Vovelle, G. Moréac, C. Mounaïm-Rousselle, F. Mauss, Modelling of aromatics and soot formation from large fuel molecules, Proc. Combust. Inst. 32 (2009) 753-759.

[23] H. Wang, M. Yao, Z. Yue, M. Jia, R.D. Reitz, A reduced toluene reference fuel chemical kinetic mechanism for combustion and polycyclic-aromatic hydrocarbon predictions, Combust. Flame 162 (2015) 2390-2404.

[24] H. Wang, R.D. Reitz, M. Yao, B. Yang, Q. Jiao, L. Qiu, Development of an n-heptane-n-butanol-PAH mechanism and its application for combustion and soot prediction, Combust. Flame 160 (2013) 504-519.

[25] A. Raj, I.D.C. Prada, A.A. Amer, S.H. Chung, A reaction mechanism for gasoline surrogate fuels for large polycyclic aromatic hydrocarbons, Combust. Flame, 159 (2012) 500-515.

[26] O. Mannaa, M.S. Mansour, W.L. Roberts, S.H. Chung, Laminar burning velocities at elevated pressures for gasoline and gasoline surrogates associated with RON, Combust. Flame 162 (2015) 2311-2321.

[27] C.K. Westbrook, F.L. Dryer, Chemical kinetics and modeling of combustion processes, Proc. Combust. Inst. 18 (1981) 749-767. 
[28] W.K. Metcalfe, S.M. Burke, S.S. Ahmed, H.J. Curran, A hierarchical and comparative kinetic modeling study of C1-C2 hydrocarbon and oxygenated fuels, Int. J. Chem. Kinet., 45 (2013) 638-675.

[29] S.M. Burke, W.K. Metcalfe, O. Herbinet, F. Battin-Leclerc, F.M. Haas, J. Santner, F.L. Dryer, H.J. Curran, An experimental and modeling study of propene oxidation. Part 1: Speciation measurements in jet-stirred and flow reactors, Combust. Flame 161 (2014) 2765-2784.

[30] D. Darcy, H. Nakamura, C.J. Tobin, M. Mehl, W.K. Metcalfe, W.J. Pitz, C.K. Westbrook, H.J. Curran, A high-pressure rapid compression machine study of n-propylbenzene ignition, Combust. Flame, 161 (2014) 6574.

[31] Y. Wang, A. Raj, S.H. Chung, A PAH growth mechanism and synergistic effect on PAH formation in counterflow diffusion flames, Combust. Flame, 160 (2013) 1667-1676.

[32] M. Mehl, W.J. Pitz, C.K. Westbrook, H.J. Curran, Kinetic modeling of gasoline surrogate components and mixtures under engine conditions, Proc. Combust. Inst. 33 (2011) 193-200.

[33] A. Raj, M.J. Al Rashidi, S.H. Chung, S.M. Sarathy, PAH growth initiated by propargyl addition: Mechanism development and computational kinetics, J. Phys. Chem. A, 118 (2014) 2865-2885.

[34] R.D. Kern, Q. Zhang, J. Yao, B.S. Jursic, R.S. Tranter, M.A. Greybill, J.H. Kiefer, Pyrolysis of cyclopentadiene: Rates for initial C- H bond fission and the decomposition of c-C5H5, Proc. Combust. inst., 27 (1998) 143-150.

[35] L. Zhang, J. Cai, T. Zhang, F. Qi, Kinetic modeling study of toluene pyrolysis at low pressure, Combust. Flame 157 (2010) 1686-1697.

[36] CHEMKIN-PRO 15112, Reaction Design, San Diego, 2011.

[37] S. Park, O. Mannaa, F. Khaled, R. Bougacha, M.S. Mansour, A. Farooq, S.H. Chung, S.M. Sarathy, A comprehensive experimental and modeling study of 2-methylbutanol combustion, Combust. Flame 162 (2015) 2166-2176.

[38] H. Selim, S.Y. Mohamed, A. Lucassen, N. Hansen, S.M. Sarathy, Effect of the methyl substitution on the combustion of two methylheptane isomers: Flame chemistry using vacuum-ultraviolet (VUV) photoionization mass spectrometry, Energy Fuels 29 (2015) 2696-2708.

[39] S.M. Sarathy, U. Niemann, C. Yeung, R. Gehmlich, C.K. Westbrook, M. Plomer, Z. Luo, M. Mehl, W.J. Pitz, K. Seshadri, M.J. Thomson, T. Lu, A counterflow diffusion flame study of branched octane isomers, Proc. Combust. inst., 34 (2013) 1015-1023.

[40] N. Liu, S.M. Sarathy, C.K. Westbrook, F.N. Egolfopoulos, Ignition of non-premixed counterflow flames of octane and decane isomers, Proc. Combust. inst., 34 (2013) 903-910.

[41] K.T. Kang, J.Y. Hwang, S.H. Chung, Soot zone structure and sooting limit in diffusion flames: Comparison of counterflow and co-flow flames, Combust. Flame 109 (1997) 266-281.

[42] Y. Wang, S.H. Chung, Effect of strain rate on sooting limits in counterflow diffusion flames of gaseous hydrocarbon fuels: Sooting temperature index and sooting sensitivity index, Combust. Flame 161 (2014) 12241234.

[43] Y. Wang, S.H. Chung, Strain rate effect on sooting characteristics in laminar counterflow diffusion flames, Combust. Flame 165 (2016) 433-444. 
[44] A. Ciajolo, R. Barbella, A. Tregrossi, L. Bonfanti, Spectroscopic and compositional signatures of pahloaded mixtures in the soot inception region of a premixed ethylene flame, Proc. Combust. Inst. 27 (1998) 1481-1487.

[45] A. Ciajolo, R. Ragucci, B. Apicella, R. Barbella, M. de Joannon, A. Tregrossi, Fluorescence spectroscopy of aromatic species produced in rich premixed ethylene flames, Chemosphere, 42 (2001) 835-841.

[46] S.M. Lee, S.S. Yoon, S.H. Chung, Synergistic effect on soot formation in counterflow diffusion flames of ethylene-propane mixtures with benzene addition, Combust. Flame 136 (2004) 493-500.

[47] I. Berlman, Handbook of florescence spectra of aromatic molecules, Elsevier 2012.

[48] K. Fieweger, R. Blumenthal, G. Adomeit, Self-ignition of S.I. engine model fuels: A shock tube investigation at high pressure, Combust. Flame 109 (1997) 599-619.

[49] J. Herzler, M. Fikri, K. Hitzbleck, R. Starke, C. Schulz, P. Roth, G.T. Kalghatgi, Shock-tube study of the autoignition of $\mathrm{n}$-heptane/toluene/air mixtures at intermediate temperatures and high pressures, Combust. Flame 149 (2007) 25-31.

[50] B.M. Gauthier, D.F. Davidson, R.K. Hanson, Shock tube determination of ignition delay times in fullblend and surrogate fuel mixtures, Combust. Flame 139 (2004) 300-311.

[51] S.G. Davis, C.K. Law, Laminar flame speeds and oxidation kinetics of iso-octane-air and n-heptane-air flames, Proc. Combust. Inst. 27 (1998) 521-527.

[52] J.P.J. Van Lipzig, E.J.K. Nilsson, L.P.H. de Goey, A.A. Konnov, Laminar burning velocities of n-heptane, iso-octane, ethanol and their binary and tertiary mixtures, Fuel 90 (2011) 2773-2781.

[53] L. Sileghem, V.A. Alekseev, J. Vancoille, K.M. Van Geem, E.J.K. Nilsson, S. Verhelst, A.A. Konnov, Laminar burning velocity of gasoline and the gasoline surrogate components iso-octane, $\mathrm{n}$-heptane and toluene, , Fuel 112 (2013) 355-365.

[54] S.G. Davis, H. Wang, K. Breinsky, C.K. Law, Laminar flame speeds and oxidation kinetics of benzene-air and toluene-air flames, Proc. Combust. Inst. 26 (1996) 1025-1033.

[55] R.J. Johnston, J.T. Farrell, Laminar burning velocities and Markstein lengths of aromatics at elevated temperature and pressure, Proc. Combust. Inst. 30 (2005) 217-224.

[56] A.E. Bakali, J.L. Delfau, C. Vovelle, Experimental study of 1 atmosphere, rich, premixed n-heptane and iso-octane flames, Combust. Sci. Technol. 140 (1998) 69-91.

[57] P. Berta, I.K. Puri, S.K. Aggarwal, Structure of partially premixed n-heptane-air counterflow flames, Proc. Combust. Inst. 30 (2005) 447-453.

[58] P. Selvaraj, P.G. Arias, B.J. Lee, H.G. Im, Y. Wang, Y. Gao, S. Park, S.M. Sarathy, T. Lu, S.H. Chung, A computational study of ethylene-air sooting flames: Effects of large polycyclic aromatic hydrocarbons, Combust. Flame 163 (2016) 427-436.

[59] Y. Wang, A. Raj, S.H. Chung, Soot modeling of counterflow diffusion flames of ethylene-based binary mixture fuels, Combust. Flame 162 (2015) 586-596.

[60] J.Y. Hwang, S.H. Chung, Growth of soot particles in counterflow diffusion flames of ethylene, Combust. Flame 125 (2001) 752-762.

[61] A. Raj, M. Sander, V. Janardhanan, M. Kraft, A study on the coagulation of polycyclic aromatic hydrocarbon clusters to determine their collision efficiency, Combust. Flame 157 (2010) 523-534. 
[62] J. Appel, H. Bockhorn, M. Frenklach, Kinetic modeling of soot formation with detailed chemistry and physics: laminar premixed flames of C2 hydrocarbons, Combust. Flame 121 (2000) 122-136.

[63] F. Ossler, T. Metz, M. Alden, Picosecond laser-induced fluorescence from gas-phase polycyclic aromatic hydrocarbons at elevated temperatures. I. Cell measurements, Appl. Phys. B, 72 (2001) 465-478.

[64] C. Ji, S.M. Sarathy, P.S. Veloo, C.K. Westbrook, F.N. Egolfopoulos, Effects of fuel branching on the propagation of octane isomers flames, Combust. Flame 159 (2012) 1426-1436.

[65] S.M. Sarathy, U. Niemann, C. Yeung, R. Gehmlich, C.K. Westbrook, M. Plomer, Z. Luo, M. Mehl, W.J.

Pitz, K. Seshadri, M.J. Thomson, T. Lu, A counterflow diffusion flame study of branched octane isomers, Proc. Combust. Inst. 34 (2013) 1015-1023. 